\title{
Polymeric composite materials for radiation shielding: a review
}

\author{
Chaitali V. More ${ }^{1}\left[\right.$ ] Zainab Alsayed $^{2} \cdot$ Mohamed. S. Badawi $^{2} \cdot$ Abouzeid. A. Thabet $^{3} \cdot$ Pravina P. Pawar $^{1}$
}

Received: 24 October 2020 / Accepted: 19 January 2021 / Published online: 3 February 2021

(c) The Author(s), under exclusive licence to Springer Nature Switzerland AG part of Springer Nature 2021

\begin{abstract}
The rising use of radioactive elements is increasing radioactive pollution and calling for advanced materials to protect individuals. For instance, polymers are promising due to their mechanical, electrical, thermal, and multifunctional properties. Moreover, composites made of polymers and high atomic number fillers should allow to obtain material with low-weight, good flexibility, and good processability. Here we review the synthesis of polymer materials for radiation protection, with focus on the role of the nanofillers. We discuss the effectivness of polymeric materials for the absorption of fast neutrons. We also present the recycling of polymers into composites.
\end{abstract}

Keywords Ionizing radiation - Gamma radiation · Polymer composite materials · Polymer recycling and radiation shielding

$\begin{array}{lll}\text { Abbreviations } & & \mathrm{WO}_{3} \\ \gamma \text {-rays } & \text { Gamma rays } & \mathrm{EPVC} \\ \mathrm{Z} & \text { Atomic number } & \text { PolyBiz } \\ \mathrm{Bq} & \text { Becquerel } & \rho \\ \mathrm{C} & \text { Carbon } & M \\ \mathrm{H} & \text { Hydrogen } & V \\ \mathrm{O} & \text { Oxygen } & I_{0} \\ \mathrm{~N} & \text { Nytrogen } & I \\ \mathrm{Ba} & \text { Barium } & \mu_{\mathrm{m}} \text { or } \mu / \rho \\ \mathrm{Pb} & \text { Lead } & W_{i} \\ \mathrm{Al} & \text { Aluminium } & A_{i} \\ \mathrm{Cu} & \text { Copper } & a_{i} \\ \mathrm{Fe} & \text { Iron } & Z_{\mathrm{eff}} \\ \mathrm{Bi} & \text { Bismuth } & \sigma_{\mathrm{atm}} \text { or } \sigma_{\mathrm{a}} \\ \mathrm{Bi} \mathrm{O}_{3} & \text { Bismuth oxide } & \sigma_{\mathrm{e}} \text { or } \sigma_{\mathrm{el}} \\ \mathrm{W} & \text { Tungsten } & \sigma_{\mathrm{t}} \text { or } \sigma_{\mathrm{tot}} \\ \mathrm{MoS}_{2} & \text { Molybdenum disulfide } & \sigma_{\mathrm{m}} \text { or } \sigma_{\mathrm{mol}} \\ \mathrm{B}_{4} \mathrm{C} & \text { Boron carbide } & f_{\mathrm{i}} \\ \mathrm{PE} & \text { Polyethylene } & \\ \mathrm{HDPE} & \text { High density polyethylene } & N_{\mathrm{e}} \text { or } N_{\mathrm{eff}} \\ & & \langle A\rangle\end{array}$

Chaitali V. More

chaitalimore89@gmail.com

1 Department of Physics, Dr. Babasaheb Ambedkar Marathwada University, Aurangabad, MS, India

2 Department of Physics, Faculty of Science, Beirut Arab University, Beirut, Lebanon

3 Department of Medical Equipment Technology, Faculty of Allied Medical Sciences, Pharos University in Alexandria, Alexandria, Egypt
Tungsten trioxide

Emulsion polyvinyl chloride

Polymer bricks

Density

Mass

Volume

Un-attenuated photon intensity

Attenuated photon intensity

Mass attenuation coefficient

Weight fraction

Atomic weight of $i$ th element

Number of formula units

Effective atomic number

Total atomic cross-section

Electronic cross-section

Total cross-section

Total cross-section

Fractional abundance of $i$ th constituent element

Effective electron density

Average atomic mass of the material

Relaxation length

Linear attenuation coefficient

Molar extinction coefficient

Equivalent atomic number

Energy absorption build-up

factor

EBF $\quad$ Exposure build-up factor 


\begin{tabular}{|c|c|c|c|}
\hline$\sum_{R}$ & $\begin{array}{l}\text { Macroscopic removal cross- } \\
\text { section for fast neutrons }\end{array}$ & $\begin{array}{l}\mathrm{Pb}_{3} \mathrm{O}_{4} \\
\mathrm{WO}_{3}\end{array}$ & $\begin{array}{l}\text { Lead tetraoxide } \\
\text { Tungsten oxide }\end{array}$ \\
\hline HVT & Half value layer & $\mathrm{ZrO}_{2}$ & Zirconium dioxide \\
\hline TVL & Tenth value layer & UHMWPE & Ultra-high-molecular-weight \\
\hline RPE & Radiation protection efficiency & & polyethylene \\
\hline G-P fitting method & $\begin{array}{l}\text { Geometric-progression fitting } \\
\text { method }\end{array}$ & $\mathrm{P}(\mathrm{VDF}-\mathrm{TrFE})$ & $\begin{array}{l}\text { Poly(vinylidene } \\
\text { fluoride-tryfluorethylene) }\end{array}$ \\
\hline POM & Polyoxymethylene & EVA & Ethylene vinyl acetate copolymer \\
\hline PAN & Polyacrylonitrile & $\mathrm{CB}$ & Carbon black \\
\hline NR & Natural rubber & $\mathrm{W}$ & Tungsten \\
\hline PMA & Polymethyl acrylate & HSC & Hematite-serpentine concrete \\
\hline PPM & Poly-phenyl-methacrylate & $\mathrm{CdO}$ & Cadmium oxide \\
\hline PET & Polyethylene terephthalate & Pd/Ag alloy & Palladium/silver alloy \\
\hline (PA-6) & Polyamide (Nylon 6) & PVA-PEG-PVP-ZrO & Polyvinyl alcohol-polyethylene \\
\hline PAN & Polyacrylonitrile & & glycol-polyvinyl pyrrolidinone \\
\hline PVDC & Polyvinylidene chloride & & with zirconium oxide \\
\hline PANI & Polyaniline & VMQ & Methyl vinyl silicone rubber \\
\hline PET & Polyethylene terephthalate & $\mathrm{Al}_{2} \mathrm{O}_{3}$ & Aluminium oxide \\
\hline PPS & Polyphenylene sulfide & PDMS & Polydimethylsiloxane \\
\hline PPy & Polypyrrole & WC & Tungsten carbide \\
\hline PTFE & Polytetrafluoroethylene & W-BN & Tungsten-boron nitride \\
\hline PVC & Polyvinyl chloride & EVA & Ethylene-vinyl acetate \\
\hline PMMA & Polymethyl methacrylate & CMT & Colemanite \\
\hline DMSO & Dimethyl sulfoxide & CMW & Coal mining waste \\
\hline PEI & Polyethylenimine & $\mathrm{CaCO}_{3}$ & Calcium carbonate \\
\hline PVA & Poly(vinyl alcohol) & CFRTPCs & Carbon fiber reinforced thermo- \\
\hline MCNP code & Monte Carlo N-particle code & & plastic composites \\
\hline $\mathrm{NaI}(\mathrm{Tl})$ & Thallium doped sodium iodide & COD & Chemical oxygen demand \\
\hline SGS & Sol-gel synthesis & SPR & Smoke production rate \\
\hline NPs & Nano particles & THR & Total heat release \\
\hline IMS & Intermatrix synthesis & TPU & Thermoplastic polyurethane \\
\hline SBR & Styrene-butadiene rubber & LBS & Lead-bearing sludge \\
\hline $\mathrm{Fe}_{2} \mathrm{O}_{3}$ & Ferric oxide & ABS & Poly(acrylonitrile-butadiene- \\
\hline $\mathrm{ZnO}$ & Zinc oxide & & styrene) \\
\hline $\mathrm{MoO}$ & Molybdenum oxide & WrPC & Recycled plastic composite \\
\hline $\mathrm{TiO}_{2}$ & Titanium dioxide & UPR & Unsaturated polyester resin \\
\hline $\mathrm{ABS}$ & Acrylonitrile butadiene styrene & $\mathrm{Pb}\left(\mathrm{NO}_{3}\right)_{2}$ & Lead nitrate \\
\hline PLA & Polylactic acid & $\mathrm{CeO}_{2}$ & Cerium dioxide \\
\hline 3D & 3 Dimensional & Cs & Cesium \\
\hline $\mathrm{PC}$ & Polycarbonate & $\mathrm{Am}$ & Americium \\
\hline $\mathrm{wt} \%$ & Weight percent & I & Iodine \\
\hline PEEK & Poly-ether-ether-ketone & Co & Cobalt \\
\hline IMS & Intermatrix synthesis & Gy & Gray \\
\hline BNP & Bismuth nitrate pentahydrate & MCM & Mobil composition of matter \\
\hline
\end{tabular}

$\mathrm{Gd}_{2} \mathrm{O}_{3}$

PVDF

Gadolinium oxide

Polyvinylidene difluoride

$\mathrm{BaTiO}_{3}$

Barium titanate

Introduction

$\mathrm{CaWO}_{4} \quad$ Calcium tungsten oxide

LDPE Low-density polyethylene

PS Polystyrene

PP Polypropylene

PVP Polyvinyl pyrrolidone

$\mathrm{PbO} \quad$ Lead oxide

Radiation is energy that comes from a source and travels through space and may be able to penetrate various materials. Radiation can be classified according to its capability to ionize matter into two main categories: (1) ionizing radiation and (2) nonionizing radiation (Singh et al. 2014a, 
b). Nonionizing radiation does not possess enough energy to eject electrons from the atom and produce ions such as visible light, microwaves, radio waves, alpha, beta particles from radioactive substances, or neutrons from nuclear reactors, infrared, and sunlight (Oto et al. 2015). Ionizing radiation is electromagnetic radiation that carries higher energy than nonionizing radiation that makes them capable of ejecting electrons from atoms and produces negatively charged free electrons and positively charged ionized atoms. Ionizing radiation consists of any types of photons (X-rays and gamma $(\gamma)$-rays) or particles (alpha, beta, and neutrons) (Harish et al. 2012).

The use of high-energy ionizing radiations especially gamma rays is rapidly growing in many sectors like industries, nuclear reactors, medical diagnostics, nuclear research establishment, food irradiation, nuclear waste storage sites, biological studies, defects detecting in metal castings nuclear medical imaging, and therapy, space exploration, and highenergy physics experiments, and so on (Sayyed et al. 2017a, b). Inadvertent exposure to gamma rays which possess a highly energetic and penetrating nature is of great concern due to its detrimental effects on human life, the environment, and other materials. Further, for humans, this can engender radiation sickness, organ damage, cell mutation, cancer, component failure, and other harmful effects (Sayyed et al. 2019). Therefore, protection from the inimical effects of radiation for the human population and the environment is very important and it depends on four important factors: time, distance, shielding, and activity. By minimizing exposure time and increasing the distance, the dose from the source of radiation can be reduced. Since the distance from the source follows inverse square law which means that if the distance is doubled, then the dose/dose rate at the new location will quarter (Woodhead 2002). The activity, measured in Becquerel (Bq), is defined as the strength of a radioactive source which represents the number of atoms that decay and emit radiation in one second. Radioactive substances of different activities contain different hazards and thus must be handled accordingly (Choppin et al. 2002). Shielding is generally preferred for radiation protection. Shielding has merits such as it has independent efficacy in safe working conditions over the time of exposure and distance that require continued managerial regulation (Vahabi et al. 2017). Thus, an appropriate shielding against nuclear radiation is constantly in demand for a secure life and a healthy environment as the radiation uses are consistently viable in various human activities (Kumar 2017).

Researchers have investigated various radiation shielding materials to protect life and its surroundings from debasing consequences that occurred from radiation exposure under attenuation or absorption of unwanted radiations (Singh et al. 2014a, b; Al-Buriahi et al. 2020; Levet et al. 2020; More et al. 2020a, b; Rani et al. 2020). Weight, space, cost, and attenuation or absorption capabilities of the materials used for radiological protection are key points that defy researchers to synthesize and develop appropriate shielding materials. A good radiation shield is one that can attenuate, absorb, or block the maximum part of incident gamma radiation. The nature and mechanism of interaction between gamma rays and materials is a critical issue to study to determine the ability of these radiations to diffuse and crack in the medium that according to the mechanism of interaction helps to choose the more applicable radiation shield. Materials that are supposed to be used as shields against gamma photons should have higher atomic number and density as such materials impose a higher probability of interactions that implies larger energy transfer with gamma rays (Chang et al. 2015). Withal, materials with lower atomic number (lower-Z) and density can make up of increased thickness as significantly as high atomic number (high-Z) materials in radiation protection (Luković et al. 2015; Mostafa et al. 2017). Customarily, lead, multiple layers of single slabs of pure elements such as barium $(\mathrm{Ba})$, lead $(\mathrm{Pb})$, aluminum $(\mathrm{Al})$, copper $(\mathrm{Cu})$, iron $(\mathrm{Fe})$, and concrete are reliable efficient materials that prevent humans from getting affected by the obnoxious effects of ionizing radiations (Sayyed et al. $2017 \mathrm{a}, \mathrm{b}$ ). Despite having great radiation attenuation properties, lead and concrete are discarded due to the heterogeneous nature of lead, and moisture variation in concretes makes it hard to predict radiation protection (Singh et al. 2015) and insidious hazards are proposed by lead to human health and the environment (Thuyavan et al. 2015). In contrast to the past, polymer and its composites offer promising suitable alternative candidates to lead and concrete in the field of radiation shielding due to its lightweight, durability, flexibility along with superior physical, mechanical, optical, and radiation resistance properties (Ambika et al. 2017; Alavian et al. 2020). Besides, polymers can easily be doped with sizeable amounts of high atmic number (high-Z) materials to form their composites that are more competent radiation shields (Atashi et al. 2018).

Latterly, investigators working in the field of radiation protection have focused and reported numerous polymer matrices that can be used as gamma-ray shields like bismuth oxide $\left(\mathrm{Bi}_{2} \mathrm{O}_{3}\right)$ filled poly (methyl methacrylate) composites; high-density polyethylene (HDPE) composite loaded with tungsten $(\mathrm{W})$, molybdenum sulfide $\left(\mathrm{MoS}_{2}\right)$, and boron carbide $\left(\mathrm{B}_{4} \mathrm{C}\right)$; micro- and nanosized tungsten oxide $\left(\mathrm{WO}_{3}\right)$ dispersed emulsion polyvinyl chloride (EPVC) polymer composites; lead oxide filled isophthalic resin polymer composites; silicone rubber composites containing bismuth content; polymer bricks (PolyBiz); polyester composites reinforced with zinc; composites of high-density polyethylene with zinc oxide; lead oxide; and cadmium oxide (Plionis et al. 2009; El-Fiki et al. 2015; Aghaz et al. 2016; Mahmoud 
et al. 2018a, b; Afshar et al. 2019; Alsayed et al. 2019, 2020; El-Khatib et al. 2019; Cao et al. 2020; Kaçal et al. 2020).

The incorporation of a filler in a microsize range within the composite material leads to the enhancement of composite properties. Chemical and intermolecular forces render the bond between the polymer and the matrix. But on the nanometer scale, a nanofiller can be dispersed within the polymer matrix. Thus, the molecular interactions between the matrix and the filler are improved via chemical bonding leading to further enhancement in the mechanical and physical properties of the new polymer nanocomposites (Kumar et al. 2009). Nanofillers are characterized by a high surfaceto-volume ratio which affects the alteration in the macromolecular state around the nanoparticles. The addition of nanofiller enhances the characteristics of the polymer such as increased elastic stiffness and strength, heat and barrier resistance, decreased gas permeability, and flammability. The optical, magnetic, electrical, and dielectric properties are also enhanced (Phong et al. 2013; Kumar et al. 2014). Another aspect that signifies the use of nanoparticles as additives to the polymer matrix is that the loading requirements are quite low compared to others. Various types of inorganic nanomaterials such as zeolite, zinc oxide, titanium oxide, and silicon dioxide were used with nanoclay materials to manufacture nanocomposite membrane which is effective in removing salts and minerals from seawater by process called desalination (Hebbar et al. 2017). Moreover, intensive recent studies focus on the evidence of low toxicity of mostly used nanoparticles such as copper, silver, and titania nanoparticles which were found to be having low toxicity in various natural media when to subjected oxic/anoxic suspension, and incubation with natural organic matter (Mulenos George et al. 2020).

Generally, polymers have very low mechanical characteristics but are useful because of their flexibility in applications requiring such a property. They are usually deformed at high strain under loading. The improvement in mechanical properties such as tensile strength, modulus, or stiffness is done by adding inorganic particles via reinforcement mechanisms. Such properties can indeed be tailored by changing the volume fraction, shape, and size of the filler particles. The better enhancement in mechanical properties can be gained with the reinforcement of nanofillers having a very large aspect ratio and stiffness in a polymer matrix (Bhattacharya 2016). Polymer nanocomposites offer the promise of a new generation of lightweight hybrid materials with numerous possibilities for automotive, general, and industrial applications. It includes the potential for utilization as radiation shielding materials over traditional materials. The high kinetic energy of neutrons makes them capable of passing through most materials and interacts immediately with atoms of the target material. Neutrons are generally used for the production of nuclear energy in nuclear power plants and workers there get exposed to neutrons. Besides them, aircraft personnel is prone to exposure to neutrons. Exposure to neutrons is considered critical due to the detrimental effects on the human body as they generate much denser ion paths while they deposited their energy (Mirji and Lobo 2017a, b). Thus, there is a demand for efficient, durable, lightweight, and cost-effective materials to get protected from different types of radiation.

Since polymer composites are considered cornerstone's as engineering materials for many applications such as building, civil engineering, aerospace technology, electronics, and electrical engineering (Alavian and Tavakoli-Anbaran 2020). In addition, an important issue to be considered is the surface functionalization of polymer composites when nano-objects are added to ameliorate the performance of the synthesized material (Makvandi et al. 2020). An interesting problem arises from the use and storage of polymer composite materials as wastes. The accumulation of wastes from polymer composite materials can lead to a serious burden on humans and the environment by causing pollution to nature.

Recently, many researchers dedicated their efforts to develop new technologies for recycling and treatment of polymer composite materials waste (Turner et al. 2011). Recycling and incorporation of different filler materials in recycled polymers which can be easily composted (Adeosun et al. 2012) are extremely important to provide environmentally friendly and sustainable materials (Okamoto 2003). Many attempts have been dedicated to using biodegradable fillers which at the same time can enhance the performance of the composite (Lee et al. 2008; Qu et al. 2010). Other researchers were concerned about developing thermoplastic composites with recyclable fibers to diminish the use of fillers without any harm to the environment and keeping it clean and healthy (Kaushik et al. 2010; Zadegan et al. 2011).

In this review, the leading edge of polymer and its composites especially with nanomaterials' as radiation-shielding materials are epitomized. In "Polymers properties and applications" section, the properties of polymer materials have been discussed. "Physical and radiation shielding properties" section gives information about physical and radiation shielding properties of polymer materials, whereas "Polymers used in radiological protection" gives an overview and historical perspective along with a brief literature review of the polymer materials. In Sect. 5, synthesis methods of polymer composites have been discussed. Also, the contemporaneous work on polymer materials and the development of polymer composites as promising candidates for radiation shielding is broadly categorized and a brief literature review is presented. Improvement in the shielding abilities of polymers by the incorporation of nanofillers is presented in Sect. 6. In Sects. 7 and 8, recycling of polymers and the use of processed and post-consumed polymers as composite materials for different applications were covered, 
respectively. In Sect. 9, the use of polymeric materials for neutron shielding has been covered. The comparative study of polymer composites is given in Sect. 10. Conclusions and future aspects have been outlined in Sects. 11 and 12, respectively.

\section{Polymers properties and applications}

Polymers are substances containing a large number of structural units joined by the same type of linkage. These substances often form a chain-like structure. It has been approximately 60 years since researchers first began exposing polymeric materials to ionizing radiations, and today, a substantial commercial industry is in place based on the processing of polymers with radiation. Polymers are of low atomic number and low density and thus lightweight materials. Polymers possess high durability, and they are tough. Also, they are cost-effective, need low maintenance, and stable over a wide temperature range (Alavian and Tavakoli-Anbaran 2019). Based on processing under changing temperature, polymers are categorized as thermosets and thermoplastics as listed in Fig. 1, also thermoplastics including elastomers can be divided into semicrystalline and amorphous polymers. Both the thermoset and thermoplastic polymers have some pros and cons, but thermoplastics are preferred for radiation shielding applications due to their superior properties as shown in Table 1. Also, thermoplastic polymers are highly recyclable and possess remolding abilities and eco-friendly manufacturing is possible using them (Cassagnau et al. 2007).

Polymers proved their effectiveness in wide range of applications including $\mathrm{CO}_{2}$ capture (Chatterjee and Krupadam 2018), safe gene delivery (Daima et al. 2018), dye removal (Grégorio et al. 2019), water and wastewater treatment (Lichtfouse et al. 2019), metal ions removal from wastewater (Salipira et al. 2007; Gu et al. 2018; Mao et al. 2018), and drug delivery (Parhi 2020).

\section{Physical and radiation shielding properties}

\section{Density}

"Density $(\rho)$ is a measure of mass $(M)$ per unit volume $(V)$ of a substance." Its unit is $\mathrm{g} / \mathrm{cm}^{3}$. Density is an important physical characteristic of a material that helps to decide the radiation shielding ability of a material. It is well known that the higher the density of the material, the higher will be the
Fig. 1 Polymers are categorized as thermosets and thermoplastics under changing temperature which can be divided into semicrystalline and amorphous

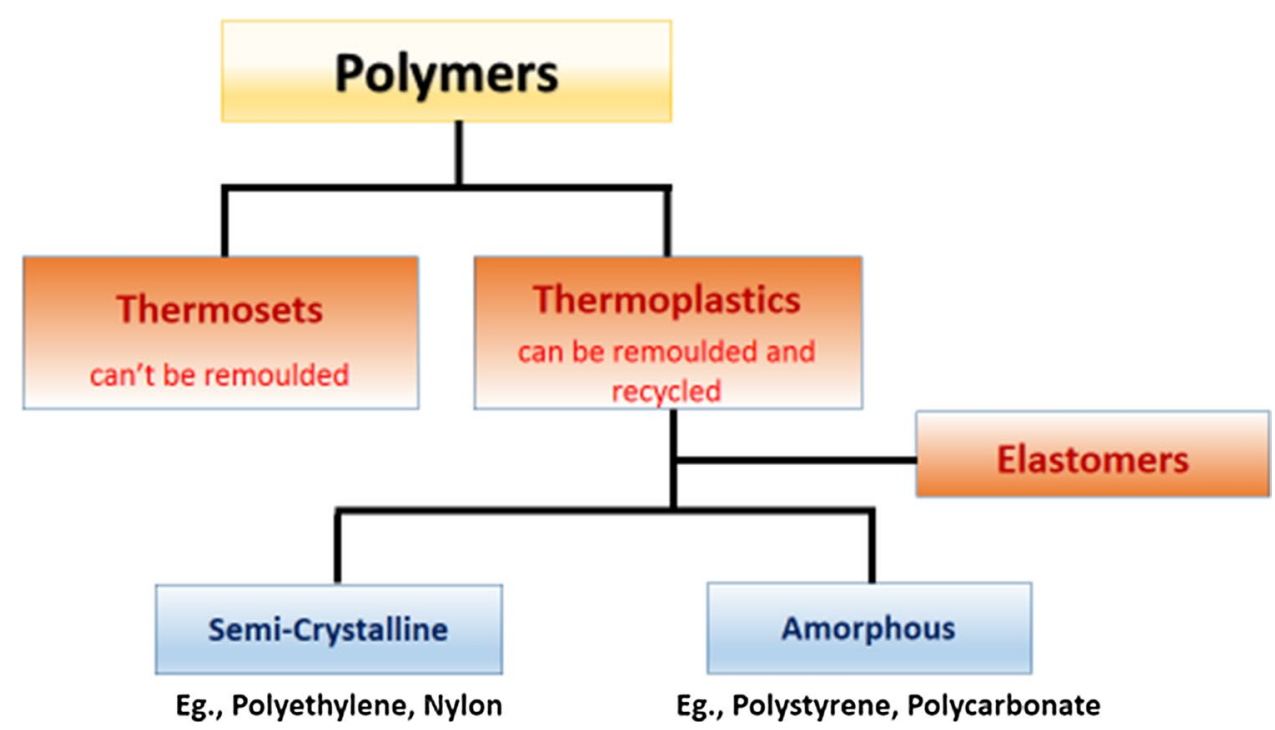

Table 1 Comparison of properties of thermoset and thermoplastic polymers (Liu and Piggott 1995; Njuguna et al. 2007)

\begin{tabular}{|c|c|c|c|c|c|}
\hline Polymer type & Toughness & User temperature & Processing time & $\begin{array}{l}\text { Solvent } \\
\text { resistance }\end{array}$ & Shear strength \\
\hline Thermoplastic & High & Low & Low & Low & High \\
\hline $\begin{array}{l}\text { Toughened thermoset } \\
\text { Lightly cross-linked } \\
\text { thermoplastic }\end{array}$ & $\begin{array}{c}\uparrow \text { Kaçal et al. } \\
(2019)\end{array}$ & $\downarrow$ & $\downarrow$ & $\downarrow$ & $\uparrow$ \\
\hline Thermoplastic & Low & High & High & High & Low \\
\hline
\end{tabular}


chance of the probability of interaction between the incident photon and absorbing material (Hellström et al. 2017).

$\rho=\frac{M}{V}$

\section{Hardness}

Hardness also known as structural strength is an important characteristic of the material that states the maximum load that the material can bear. There are several methods for calculating the hardness of a material such as young's modulus of rigidity, Rockwell hardness test, and Vickers microhardness tester. The hardness of the material makes it able to resist plastic deformation, penetration, and scratching (Chandler 1999).

\section{Linear and mass attenuation coefficients}

A parallel beam of mono-energetic gamma-ray photons is attenuated in the matter according to the Lambert-Beer law,

$I=I_{0} e^{-\left(\frac{\mu}{\rho} \times \rho t\right)}$

where $I_{0}$ and $I$ are the un-attenuated and attenuated photon intensities respectively, $t(\mathrm{~cm})$ is the sample thickness, $\mu$ $\left(\mathrm{cm}^{-1}\right)$ is the linear attenuation coefficient, and $\rho\left(\mathrm{g} / \mathrm{cm}^{3}\right)$ is a measured density of the sample (More et al. 2016).

The mass attenuation coefficient $(\mu / \rho)$ for any chemical compound or mixture of elements is given by

$\left(\frac{\mu}{\rho}\right)_{c}=\sum_{i} w_{i} \frac{\mu}{\rho}$ where $w_{i}$ is the weight fraction and $(\mu / \rho)_{i}$ is the mass attenuation coefficient of the ith constituent element. For a chemical compound, the weight fraction is given by

$w_{i}=\frac{a_{i} A_{i}}{\sum_{j} a_{j} A_{j}}$

where $A_{i}$ is the atomic weight of ith element and $a_{i}$ is the number of formula units. Figure 2 represents the schematic view of the narrow beam good geometry setup including a radioactive point source which is set based on a specific measurements, the sample, the detector, a high-voltage source (HV), an amplifier (Amp), and a multi-channel analyzer (MCA) which are all connected to a dedicated computer software.

\section{Effective atomic and electron number}

An effective atomic number $\left(Z_{\text {eff }}\right)$ is an important parameter for the determination of a substitute material for an element associated with the required energy. It fluctuates with energy, resembles the atomic number of elements, and describes the material's composition based on equivalent elements. The effective atomic number is obtained by the following equation (More et al. 2016)

$Z_{\text {eff }}=\frac{\sigma_{\mathrm{a}}}{\sigma_{\mathrm{e}}}$

Here, $\sigma_{\mathrm{a}}$ and $\sigma_{\mathrm{e}}$ are total atomic cross section and electronic cross section, respectively, and are given as follows (Sayyed et al. 2017a, b):

$\sigma_{\mathrm{a}}=\frac{\mu_{m}}{N_{A} \sum_{i} \frac{w_{i}}{A_{i}}}$
Fig. 2 Narrow beam good geometry setup including a radioactive point source which is set based on a specific measurements, the sample, the detector, a high-voltage source (HV), an amplifier (Amp), and a multichannel analyser (MCA) which are all connected to a dedicated computer software (Alsayed et al. 2020)

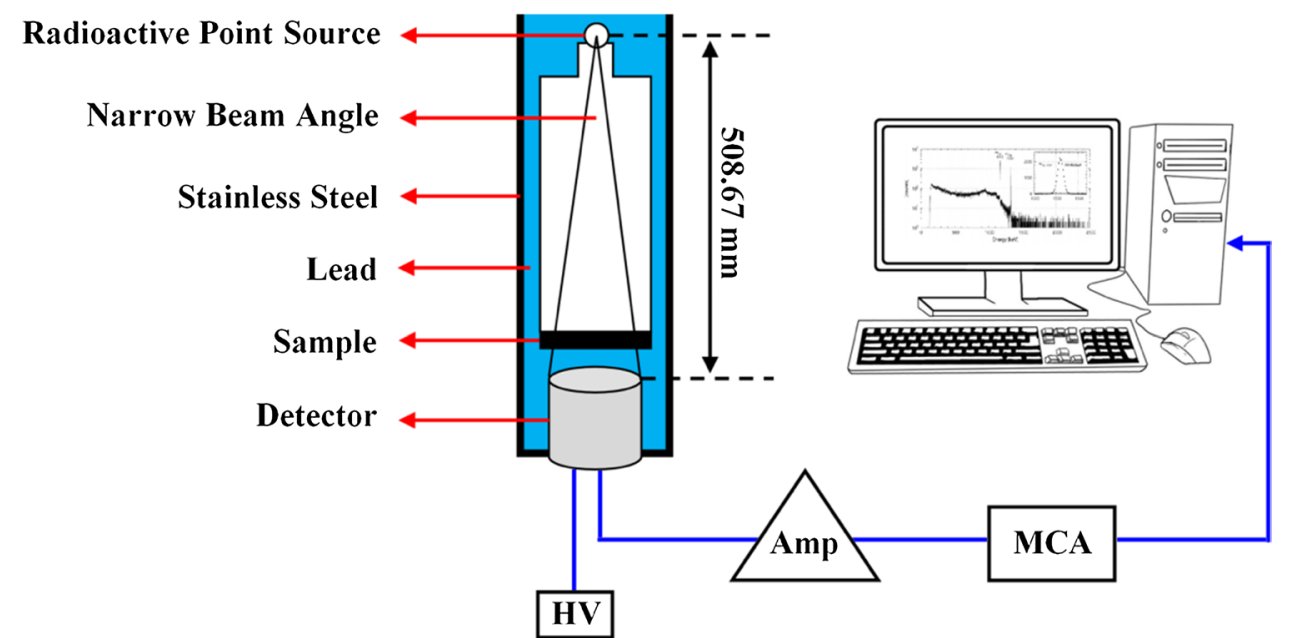


$\sigma_{\mathrm{e}}=\frac{1}{N_{A}} \sum_{i} \frac{f_{i} A_{i}}{Z_{i}}\left(\mu_{m}\right)_{i}$

where $f_{i}$ is the fractional abundance of $i$ th constituent element and it can be given as the following:

$f_{i}=\frac{n_{i}}{\sum_{i} n_{i}}$

Effective electron density $\left(N_{\text {eff }}\right)$ is related to the effective atomic number and is given in the number of electrons per unit mass by the next equation (Azadbakht and Bagheri 2019):

$N_{\text {eff }}=\frac{N_{\mathrm{A}}}{\langle A\rangle} Z_{\text {eff }}$

where $\langle\mathrm{A}\rangle$ is the average atomic mass of the material.

\section{Relaxation length}

The average distance between two successive interactions is called the relaxation length. It is also called as photon mean free path $(\lambda)$. It can be calculated using the value of the linear attenuation coefficient, $\mu\left(\mathrm{cm}^{-1}\right)$ (Akkurt and El-Khayatt 2013).

$\lambda=\frac{1}{\mu}$

\section{Half-value layer and tenth value layer}

Half-value layer (HVL) and tenth value layer (TVL) are defined as the thickness or layer of a shield or absorber that lessens the intensity of radiation by a factor of one half and one tenth of the initial intensity, respectively (Mann et al. 2016).

$\mathrm{HVL}=\frac{\ln 2}{\mu}$

$\mathrm{TVL}=\frac{\ln 10}{\mu}$

\section{Radiation protection efficiency}

The radiation protection efficiency of a material is an important parameter to know material's shielding ability and is determined as follows (Harima 1983):

$\mathrm{RPE}=\left(1-\frac{I}{I_{0}}\right) \times 100$

\section{Buildup factor}

There are several reported methods for the calculation of buildup factors (Taylor 1954; Suteau and Chiron 2005; Vahabi and Shamsaie Zafarghandi 2020). The computation of energy absorption and exposure buildup factors (EABF and EBF) using widely used G-P fitting method and equivalent atomic number for selected Polymers is given step by step as follows:

\section{Calculation of equivalent atomic number $\left(Z_{\text {eq }}\right)$}

The equivalent atomic number, $Z_{\mathrm{eq}}$, depends on the chemical composition of materials. The obtained values of Compton partial mass attenuation coefficient, $(\mu / \rho)_{\text {Comp }}$, and the total mass attenuation coefficient, $(\mu / \rho)_{\text {total }}$, values for the elements $Z=4-30$, and for the selected materials using the XCOM/WinXCom program (Berger and Spencer 1959; Berger and Hubbell 1987; Gerward et al. 2004). The equivalent atomic number, for a given material, is then determined by matching the ratio, $(\mu / \rho)_{\text {Comp }} /(\mu / \rho)_{\text {total }}$, of that material at given energy with the corresponding ratio of a pure element at the same energy. If this ratio lies between the two ratios for known elements, then the value of $Z_{\mathrm{eq}}$ is interpolated using the following formula (Singh et al. 2014a, b):

$Z_{\text {eq }}=\frac{Z_{1}\left(\log R_{2}-\log R\right)+Z_{2}\left(\log R-\log R_{1}\right)}{\left(\log R_{2}-\log R_{1}\right)}$

where $Z_{1}$ and $Z_{2}$ are the atomic numbers of elements corresponding to the $(\mu / \rho)_{\text {Comp }} /(\mu / \rho)_{\text {total }}$ ratios, $R_{1}$ and $R_{2}$, respectively, and $R$ is the corresponding ratio for a given polymer at given energy that lies between $R_{1}$ and $R_{2}$.

\section{Estimation of geometric progression (G-P) parameters}

Utilizing buildup factor data provided by American National Standards (ANSI/ANS 1991), geometric progression (G.P.) fitting parameters $\left(b, c, a, X_{\mathrm{k}}\right.$, and $d$ ) for selected polymer material in the energy range of $0.015-15 \mathrm{meV}$ up to penetration depth of 40 mean free path (mfp) is computed with the help of equivalent atomic number $\left(Z_{\text {eq }}\right)$ using interpolation formula. Interpolation values were obtained with the use of the following equation:

$P=\frac{P_{1}\left(\log Z_{2}-\log Z_{\mathrm{eq}}\right)+C P_{2}\left(\log Z_{\mathrm{eq}}-\log Z_{1}\right)}{\left(\log Z_{2}-\log Z_{1}\right)}$ 
where $P_{1}$ and $P_{2}$ are the values of the coefficients of G-P fitting parameters corresponding to the atomic numbers $Z_{1}$ and $Z_{2}$, respectively, at given energy and $Z_{\mathrm{eq}}$ is the equivalent atomic number of the selected material. $Z_{1}$ and $Z_{2}$ are the elemental atomic numbers between which the equivalent atomic number $Z$ of the chosen samples lies.

\section{Calculation of energy absorption and exposure buildup factor}

The energy absorption and exposure buildup factors for the selected samples for incident photon energies $(0.015-15 \mathrm{meV})$ up to a penetration depth of 40 mean free paths have been calculated using estimated five geometric progression (G.P.) fitting parameter which is given below (Singh et al. 2014a, b):

$$
\begin{aligned}
& B(E, X)=1+\frac{b-1}{K-1}\left(K^{x}-1\right) \quad \text { at } K \neq 1 \\
& B(E, X)=1+(b-1) \quad \text { at } K=1
\end{aligned}
$$

$K(E, x)=c x^{a}+d \frac{\tanh \left(\frac{x}{X_{k}}-2\right){ }_{-} \tanh (-2)}{1-\tanh (-2)} \quad x \leq 40 \mathrm{mfp}$

where $E$ is the source energy and $x$ is the penetration depth in the units of mean free path (mfp). Parameters $b$ and $K$ are corresponding to a buildup factor at 1 mean free path and a multiplication factor of dose through 1 mean free path (mfp) photon penetration, respectively, and $a, b, c, d$, and $X_{k}$ are geometric progression (G.P.) fitting parameters.

\section{Polymers used in radiological protection}

\section{Overview and historical perspective}

Many types of materials have been used as radiation shielding barriers to keep a safe environment for everyday practice in all radiation facilities. Many features can categorize the proper shielding material to be used including a high atomic number (high-Z) for gamma radiation shieldings such as barium (Ba), lead (Pb), and bismuth (Bi) (Kaçal et al. 2021), whereas elements of low atomic numbers are preferably used for neutron attenuation. However, many constraints burden the use of such traditional shielding materials such as the cost, heaviness, and toxicity.

The urgent need for alternative materials in radiation shielding stimulated synthesis, and manufacturing of polymeric and plastic materials, which became a cornerstone in the materials science industry. Polymers in the form of bonded molecules (Callister 2007) are proposed in the radiation shielding industry due to their significant properties such as elasticity, compatibility, low cost, and lightness which nominate them as good candidates for radiation attenuation. Furthermore, polymers are materials containing elements with a low atomic number such as carbon $(\mathrm{C})$, hydrogen $(\mathrm{H})$, oxygen $(\mathrm{O})$, and nitrogen $(\mathrm{N})$ which are extremely important in medical applications used as tissue equivalent and phantom materials that resemble the human body. Polymers are frequently used in everyday life such as industrial (Kaphle et al. 2017), research, tissue engineering (Song et al. 2018), electronics, and drug delivery (Alavian and Tavakoli-Anbaran 2020). So the interaction of polymer material with radiation determines their contribution to the fields of science and applications. Usually, materials having dense structures are better in radiation resistance due to a high degree of symmetry. The interaction between organic material and radiation is governed by many mechanisms such as oxidation, gas production, and depolymerization (Tsepelev et al. 2019; Wady et al. 2019). In polymers, radiation resistance depends on oxygen rate and volume present in the material. Organic polymer materials are characterized by lightweight, corrosion resistance, low dielectric constant, and lightness, which allow their application in many fields containing radiation hazard.

\section{Brief literature review}

Many researchers reported the use of polymers and polymer-based materials in the field of radiation shielding. This concern has been growing towards using eco-friendly and lead-free materials since lead poses a great hazard to both human health and the environment.

The X-ray and gamma radiation shielding properties of silicon polymers such as polymer A-poly dimethyl siloxane $\left(\mathrm{C}_{2} \mathrm{H}_{6} \mathrm{OSi}\right)$, polymer B-polymethyl hydro-siloxane $\left(\mathrm{CH}_{4} \mathrm{SiO}\right)$, polymer $\mathrm{C}$-per hydro-polysiloxane $\left(\mathrm{H}_{3} \mathrm{SiN}\right)$, polymer D-poly dimethyl siloxane $\left(\mathrm{C}_{2} \mathrm{H}_{6} \mathrm{Si}\right)$, polymer E-methylsilses quinoxaline $\left(\mathrm{C}_{12} \mathrm{H}_{32} \mathrm{O}_{8} \mathrm{Si}_{8}\right)$, and polymer F-silalkalyene polymer $\left(\mathrm{SiC}_{3} \mathrm{H}_{8}\right)$ were studied. So that polymethyl hydro-siloxane $\left(\mathrm{CH}_{4} \mathrm{SiO}\right)$ possessed the lowest values of half-value layer, tenth value layer and mean free path (HVL, TVL, and $\lambda$ ), and the highest attenuation coefficient (Nagaraja et al. 2020). Another type of polymer blends was prepared via compression molding, where MCNP5 simulation geometry would be suitable to study the radiation shielding performance of polyamide 6/acrylonitrile butadiene styrene blends against gamma rays for various energies (AbdelHaseiba et al. 2018). Using a spectrophotometric technique, the radiation effect of ${ }^{60} \mathrm{Co}$ gamma rays on a polycarbonate detector was investigated and the obtained results indicated that the polycarbonate revealed good performance to be used as a gamma radiation dosimeter (Galante and Campos 2010). 
Besides, polymers proved their performance and applicability in nuclear medicine as radiation shielding against Technetium-99m, where complexed grafted low-density polyethylene films revealed that the protection efficiency of complexed grafted films was higher than in grafted and virgin films (Awadallah-F and Antar 2014). Also, most frequently used polymers such as POM-polyoxymethylene, PAN—polyacrylonitrile, NR - natural rubber, PEApolymethyl acrylate, PPM-poly-phenyl-methacrylate, PET-polyethylene terephthalate (Bhosale et al. 2017) and polyamide (nylon 6) (PA-6), polyacrylonitrile (PAN), polyvinylidene chloride (PVDC), polyaniline (PANI), polyethylene terephthalate (PET), polyphenylene sulfide (PPS), polypyrrole (PPy), and polytetrafluoroethylene (PTFE) (Kaçal et al. 2019) were studied in terms of their gamma radiation attenuation. Polyacrylonitrile, natural rubber, and polyvinylidene chloride have the highest attenuation coefficient values. Furthermore, there is a remarkable increase in attenuation especially in the high energy region for barite, marble, and limra (Akkurt et al. 2009) and also for polyvinyl chloride (PVC) among six polymer and plastic materials: bone-equivalent plastic (B-100), polyvinyl chloride (PVC), air-equivalent plastic (C-552), radio chromic dye film (nylon base), polyethylene terephthalate (mylar), polymethyl methacrylate (PMMA), and concrete (NBS) in the energy range 10-1400 keV. Polyvinylidene chloride (PVC) revealed the highest shielding performance against gamma rays (Mann et al. 2015a, b). Also, resin $250 \mathrm{WD}$ revealed good performance in neutron shielding applications compared to K-resin, epoxy resin, and resin which were studied by Elmahroug et al. (2014) for gamma $(\gamma)$ ray and neutron absorption. Among the selected samples, resin $250 \mathrm{WD}$ is a good material for neutrons shielding applications. Epoxy resin and resin showed slightly better gamma rays shielding abilities than those of the other resin for applications. Using Monte Carlo simulation code, bone-equivalent plastic, polyvinylidene chloride, air-equivalent plastic, radio chromic dye film, polyethylene terephthalate, and polymethyl methacrylate was investigated in terms of values of mass attenuation coefficient and half-value layer ( $\mu_{\mathrm{m}}$ and HVL) showing that the nylon-based radio chromic dye film has better shielding effectiveness than concrete for energies above $100 \mathrm{keV}$ (Gurler and Akar Tarim 2016). Applying MCNP simulation for low atomic number (low-Z) materials such as polypropylene, perspex, bakelite, teflon, polyethylene, poly-carbonate, nylon 6-6, and polymethyl methacrylate (PMMA) polymers in the energy range of 59.5-1332.5 keV revealed good agreement with experimental and XCOM values. Thus, the used simulation geometry in the reported work can be used as an alternative method for the experiments for MCNP simulation for low- $Z$ materials (Singh et al. 2015). Also, dimethyl sulfoxide (DMSO) and polyethylenimine (PEI) polymers have been studied by (Sayyed 2016) for their possible application for $\gamma$-rays and neutron shielding. Mass attenuation coefficient $(\mu / \rho)$, effective atomic and electron number $\left(Z_{\text {eff }}\right.$ and $\left.\mathrm{Ne}\right)$ in the wide energy range of $1 \mathrm{keV}-100 \mathrm{GeV}$ along with macroscopic removal cross section for fast neutrons $\left(\sum_{R}\right)$ have been calculated. Dimethyl sulfoxide showed superior shielding properties than polyethylenimine for gamma $(\gamma)$-ray, whereas polyethylenimine is a good material for neutron absorption. Moreover, the interaction parameters linear and mass attenuation coefficient, mass energy absorption coefficients, kinetic energy released per unit mass, and equivalent atomic number $(\mu$, $\mu / \rho, \mu_{\mathrm{en}} \rho$, KERMA, and $Z_{\mathrm{eq}}$ ) of gamma rays for different materials in the wide energy range of $1 \mathrm{keV}-100 \mathrm{GeV}$ were studied for bone-equivalent plastic, air-equivalent plastic, radio chromic dye film, polyethylene terephthalate, polymethyl methacrylate (PMMA), and polyvinyl chloride (PVC) polymers. Polyvinyl chloride showed better shielding performance, and it is even superior to NBS concrete (Mann et al. 2016). Also, in the energy range, $300-2000 \mathrm{keV}$, polymers including polyethylene (PE), polystyrene, polycarbonate, poly(vinyl alcohol), polyvinyl chloride, polyethylene terephthalate, polyvinyl pyrrolidone, polytetrafluoroethylene, polypropylene, and polymethyl methacrylate showed values of mass attenuation coefficients in good agreement with NIST data $300-2000 \mathrm{keV}$ for all studied polymers. These data would use in selecting good shielding material (Mirji and Lobo 2017a, b). Vahabi et al. (2017) have reported mass attenuation coefficients for determined using MCNP4C code and XCOM program for poly-propylene, perspex, bakelite, teflon, polyethylene, polycarbonate, nylon 6-6, and polymethyl methacrylate (PMMA). It was observed that simulated results fit well with XCOM values and experimental results in the energy range of 59.5-1332.5 keV. From the results, it can be concluded that the simulation geometry used here can be used as an alternative method for the experiments. FLUKA Monte Carlo code and XCOM program were used as an efficient alternative tool to determine radiological parameters mass attenuation coefficient, relaxation length, half and tenth value layer, electronic and atomic cross section, effective atomic number, and electron density $\left(\mu_{\mathrm{m}}, \lambda, \mathrm{TVL}, \mathrm{HVL}, \sigma_{\mathrm{t}, \mathrm{e}}, \sigma_{\mathrm{t}, \mathrm{a}}, Z_{\mathrm{eff}}\right.$, and $\left.N_{\mathrm{el}}\right)$ of the polymeric materials: polytetrafluoroethylene, bakelite, polyethylene terephthalate, polypropylene, polysulfone, polystyrene, polyethylene, natural rubber, polymethyl methacrylate, and polyvinylchloride (Sharma et al. 2019). Polymers that are best suited to gamma irradiation for manufacturing N95 masks were identified. The findings showed that having the lowest (tenth and half-value layer) TVL, HVL, and mean free path (MFP), the N2 sample [polyvinylchloride (PVC)] has the best radiation attenuation performance and is the most promising mask sample when it comes to gamma-ray attenuation features (Kilicoglu et al. 2021). 
Mass attenuation coefficient $\left(\mu_{\mathrm{m}}\right)$ and other derived parameters such as linear attenuation coefficient, atomic, total and electronic cross section, effective atomic number, electron density, half-value layer, and tenth value layer ( $\mu, \sigma_{\mathrm{a}}, \sigma_{\mathrm{t}}, \sigma_{\mathrm{e}}, Z_{\mathrm{eff}}, N_{\mathrm{el},}, \lambda, \mathrm{HVL}$, and TVL) for few thermoplastic polymers with the help of $\mathrm{NaI}$ (Tl) detector and WinXCom program revealed good agreement between experimental, theoretical, and simulated values of all parameters confirming the competency of the tested polymers in nuclear medicine gamma shielding (More et al. 2020a, b). Also, using the same experimental setup, few polymers have been studied with the determination of mass attenuation coefficient, total cross section, molar extinction coefficient, effective atomic number, and electron density ( $\mu_{\mathrm{m}}, \sigma_{\mathrm{t}}, \sigma_{\mathrm{e}}, \varepsilon, Z_{\text {eff }}$, and $\left.N_{\text {eff }}\right)$ for gamma-ray shielding application using $\mathrm{NaI}(\mathrm{Tl})$ scintillation detector and XCOM program. Among the chosen samples, nylon 1,1 showed better shielding capabilities (More et al. 2017). Polymethyl methacrylate and kapton polyimide polymers were investigated and their gamma-ray attenuation parameters such as mass attenuation coefficient, total and electronic cross section, molar extinction coefficient, effective atomic number, and electron density were measured using $\mathrm{NaI}(\mathrm{Tl})$ crystal detector in the energy range 84-1330 keV. Energy absorption and exposure buildup factors have also been calculated and reported for the selected polymers (Manjunatha 2017). For a locally developed polymeric material, namely poly-boron, mass attenuation coefficient values have been computed using the analytical method for shielding application. The calculated values were compared with values calculated based on the WinXCom program, and a good agreement has been observed between these two values. Also, linear attenuation coefficients and relaxation length have been determined. Linear and mass attenuation coefficient values for poly-boron were found to be greater than those for pure polyethylene and borated polyethylene (Biswas et al. 2016).

All these studies for pure polymers for their use in radiological protection are very useful. These studies have great significance to choose a better polymer material that would be used in radiation shielding. Once getting complete information about a better polymer material, it becomes easy to reinforce it for the needed application.
Furthermore, it can be noticed that researchers have to focus on thermoplastic materials such as polyetherimide, kapton, polysulfone, polypropylene, polyether ketone, polymethyl methacrylate, poly (butylene terephthalate), poly (ether sulfone), polymethyl pentane, poly (butyl methacrylate), poly (phenylene oxide), high-density polyethylene, poly (ethylene isophthalate) and these thermoplastic materials help in control plastic pollution as they can be recycled.

\section{Preparation methods for polymer composites}

Several types of commercially available inorganic filler molecules can be incorporated in the polymer matrix to enhance their properties by the use of several synthesis methods. A few techniques for the fabrication of polymer composites are discussed below:

\section{In situ synthesis}

There are three types of in situ synthesis as follows: in situ polymerization, in situ synthesis of inorganic nanoparticles in a polymer matrix, and in situ intercalative polymerizations. In situ polymerization methods, the inorganic nanoparticles, are introduced to the monomer precursor for the desired polymer matrix in the liquid state, dispersed thoroughly, either in the presence or in the absence of a solvent, and then the monomer is polymerized with the nanofiller by adding the appropriate catalyst or initiators under certain conditions. Thermoplastic- and thermoset-based nanocomposites can be synthesized via this route.

Figure 3 reveals the in situ technique for polymer nanocomposites where nanoparticles are added to polymer matrix to form polymer nanocomposite. This method is significant and efficient for synthesizing composites starting from nanoparticles as precursors with the presence of polymer matrices. The first step in this process is explained by the nucleation of nanoparticles and their growth within the matrix of the polymer so that the aggregation of nanoparticles caused by handling and isolation is hindered. This technique represents a good advantage in terms of stabilization of the functional groups attributed to the polymer with the synthesized nanoparticles. Thus, particle size can be controlled and the
Fig. 3 In situ synthesis for polymer nanocomposites where nanoparticles are added to polymer matrix to form polymer nanocomposite

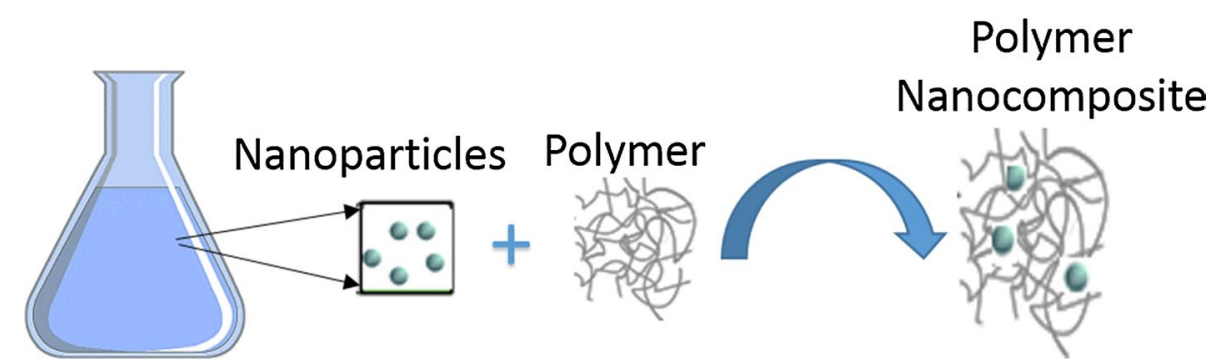


agglomeration of nanoparticles is prevented as well as good spatial distribution is maintained (Ameen et al. 2012).

In situ intercalative polymerization is a highly efficient technique with a simple procedure based on the dispersion of the filler in the polymer precursors. It is usually utilized to prepare nanocomposites based on thermoset polymers. In a monomer solution, the fillers as nanoparticles are inflated to form intercalated sheets with the polymer matrix. There are two ways to initiate the polymerization: heat and radiation via diffusing an appropriate filler as an initiator or via caption exchange taking place after nanoparticle swelling. In situ intercalative polymerization technique possesses several advantages such as it is theoretically solvent-free and combines the polymerization and intercalation steps into a single, simultaneous process (Chen et al. 2009).

\section{In situ intercalative polymerization}

In situ intercalative polymerization is a highly efficient technique with a simple procedure based on the dispersion of the filler in the polymer precursors. It is usually utilized to prepare nanocomposites based on thermoset polymers (Avella et al. 2001). In this technique, the nanofillers are swollen within the liquid monomer or a monomer solution so the polymer formation can take place between the intercalated sheets. Polymerization can be initiated either by heat or radiation, by the diffusion of a suitable initiator, or by an organic initiator or catalyst fixed through cation exchange inside the interlayer before the swelling step by the monomer. In situ intercalative polymerization technique possesses several advantages such as it is theoretically solvent-free and combines the polymerization and intercalation steps into a single, simultaneous process.

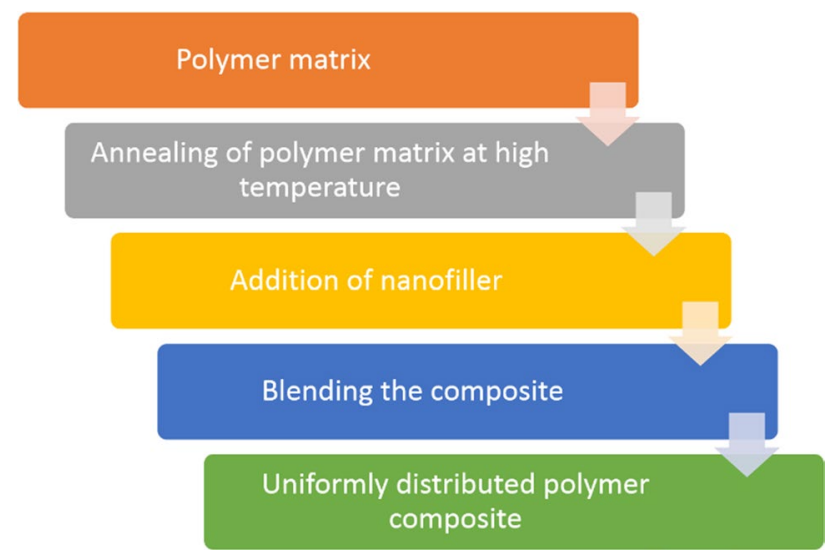

Fig. 4 Melt intercalation method steps: preparing the polymer matrix which is followed by annealing at high temperature and then adding the nanofiller, and all the mixture is blended to form a uniformly distributed polymer composite

\section{Melt intercalation}

Melt intercalation and hot pressing processes (also called melt blending method) are the typical standard approaches for synthesizing thermoplastic polymer nanocomposites. As shown by Fig. 4, it involves annealing the polymer matrix at high temperatures (above its softening point) statistically or under the shear, adding the nanofiller, and finally blending the composite to optimize the polymer-filler interactions and achieve uniform distribution. The melt intercalation technique has great advantages over either in situ intercalative polymerization of polymer solution intercalation. For example, melt intercalation is highly specific for the polymer, leading to new hybrids that were previously inaccessible. Besides, the lack of organic solvent usage makes melt intercalation an environmentally friendly and economically favorable method for industries from a waste perspective (Zeng et al. 2002).

\section{Sol-gel process}

The sol-gel synthesis (SGS) illustrated in Fig. 5 is a process of solidifying a compound which contains a highly reactive component via solgel or solution which is followed by annealing and heat treatment. This process belongs to wastefree methods, and recently, it has been employed not only to prepare organic/inorganic composites but also to provide high-performance materials at lower temperatures and lower cost. The sol-gel route has been applied broadly because of its capability to control the miscibility between organic and inorganic components at the molecular level (Camargo et al. 2009). The major advantage of the sol-gel process is the high purity, high chemical homogeneity, and rigorous stoichiometry control associated with mild conditions, such as relatively low temperature and pressure.

\section{Ultrasound cavitation}

The ultrasound cavitation technique is considered one of the most promising techniques for intensifying chemical/physical processing applications. Figure 6 summarizes the steps in the ultrasound cavitation technique; a solution containing a nanopolymer composite is prepared after mixing two solutions A and B, after that a sonicator probe is immersed, and using a pulse controller, ultrasound is applied. A sound wave consisting of successive compression (increase in local pressure) and rarefaction (decrease in local pressure) cycles is applied to a liquid. Then, the liquid starts oscillating tuned with the sound waves. Cavitation is mainly due to the generation, growth, and collapse of cavities which produce high energy densities at plenty of locations in a reactor simultaneously, thus resulting in very high conditions of pressure 


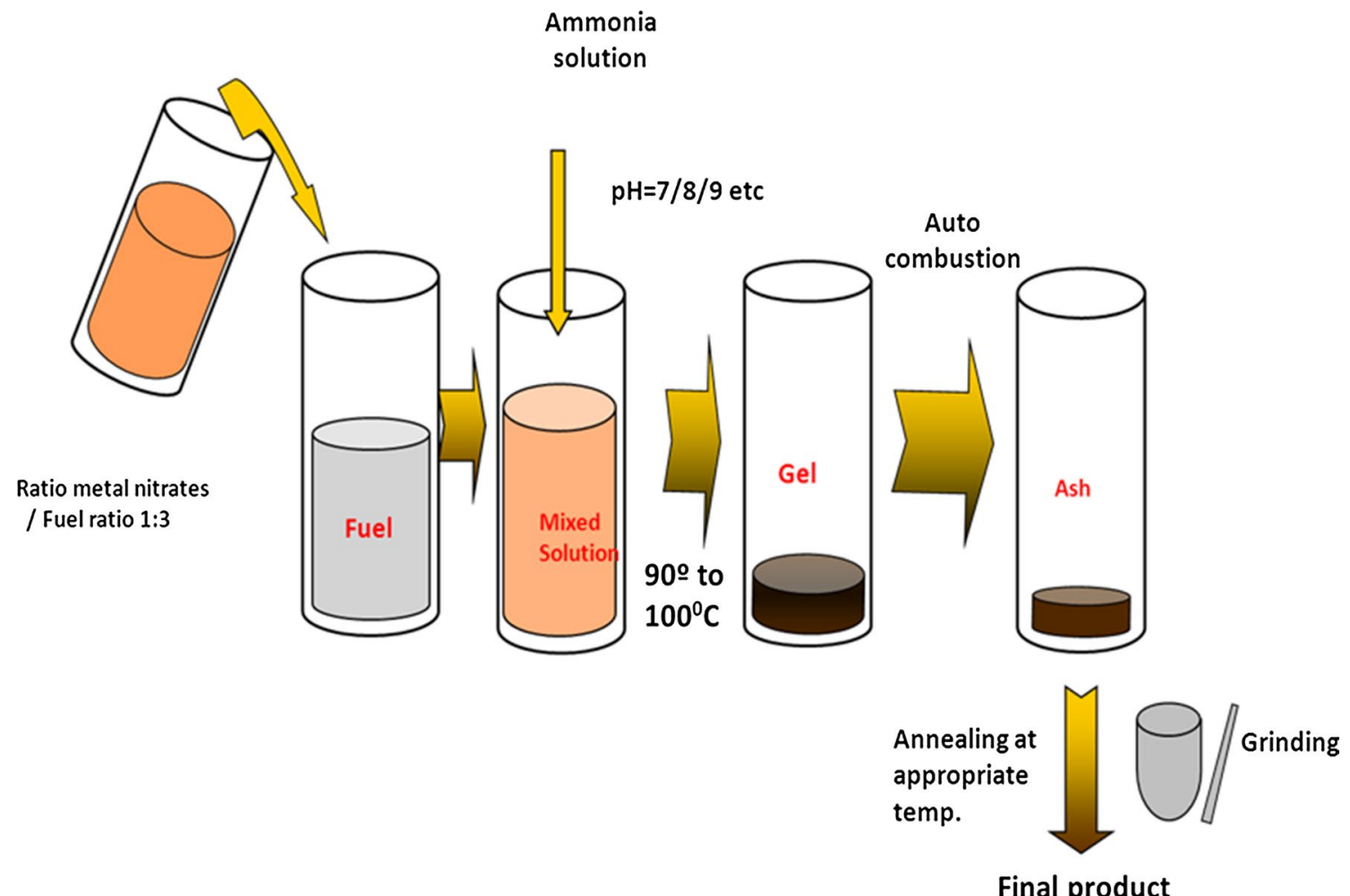

Fig. 5 Sol-gel synthesis of where a compound which contains a highly reactive component is solidified via sol-gel or solution which is followed by annealing and heat treatment

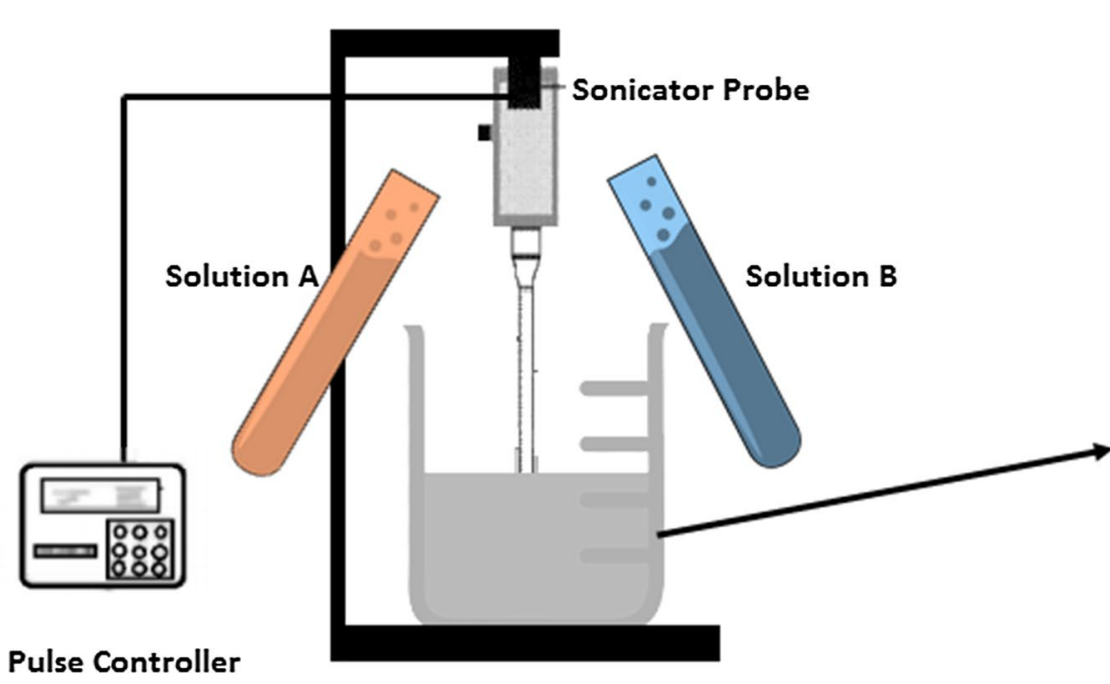

Polymer Nanocomposite

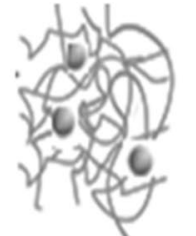

Solution C

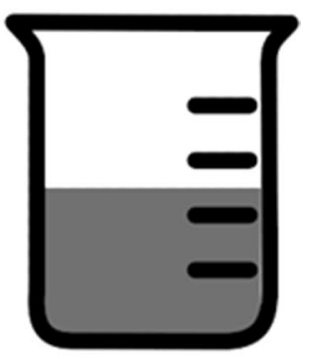

Fig. 6 Ultrasound cavitation technique in which a solution containing a nanopolymer composite is prepared after mixing two solutions A and B, and then a sonicator probe is immersed, and using a pulse controller, ultrasound is applied

and temperature locally, with the overall ambient temperature of the environment. The subsequent formation of these cavities is called cavitation. By introducing ultrasound, the cavitational energy can be used for the cracking of the petroleum residue. 
Fig. 7 Melt processing extrusion technique that involves direct mixing the host nanofillers with a polymer powder by a twin-screw extruder or blender, pressing the mixture into a pellet, and heating at the appropriate temperature

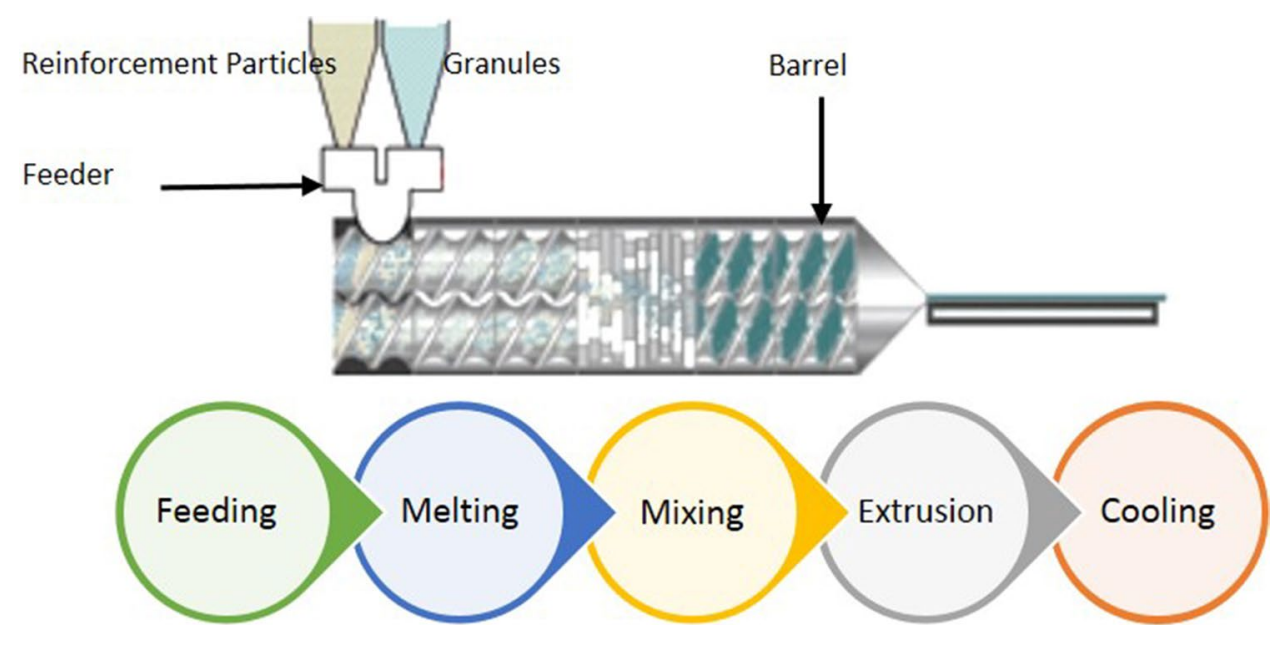

\section{Direct mixture of polymer and particulates}

Direct mixing of nanoparticles with a polymer melt in technical polymer processes, such as extrusion, is a classical method for preparing composite materials from thermoplastic polymers. As illustrated in Fig. 7, the melt processing extrusion technique involves direct mixing the host nanofillers with a polymer powder by a twin-screw extruder or blender, pressing the mixture into a pellet, and heating at the appropriate temperature.

\section{Template synthesis}

In this technique, a template is used to form nanocomposite materials of a particular shape, for example layered and hexagonal shape. The soluble polymer acts as a template for the formation of layers. The technique is based on self-assembly forces, and the polymer serves as a nucleating agent and promotes the growth of the inorganic filler crystals. As those crystals grow, the polymer is trapped within the layers and thus forms the nanocomposite. Generally, template synthesis is an easy procedure with large-scale production (Alexandre and Dubois 2000).

\section{Mechanical milling}

Mechanical milling is a well-established technique in polymer composite synthesis which involves continuous mixing with repeated high-intensity plastic deformation. These deformations can provoke composites with atomicscale dimensions. So, the main objective of this technique is to reduce the particle size and blend the particles in new phases. As illustrated in Fig. 8, the method involves the use of agate balls in a ball mill jar where the nanoparticles are milled simultaneously with the polymer to produce a polymer nanocomposite. Mechanical milling is solid-state mixing that enhances the homogeneous dispersion of filler into the polymer matrix and is a better ecological and economical alternative. It works at low temperatures and can be used for almost any type of polymer matrix. More advanced materials can be prepared when working at low temperatures, with any type of polymer, and without any extremely important solvent.

\section{Nonconventional methods}

To facilitate better dispersion of the filler in the polymer matrix for improved properties of final composites, researchers investigated different routes based on the traditional methods mentioned previously. For instance, in situ polymerization can be customized to be redox or catalytic chain transfer or even photo-induced polymerizations. Others include microwave-induced synthesis, one-pot synthesis, template-directed synthesis, electrochemical synthesis, selfassembly synthesis, and intermatrix synthesis (IMS).
Fig. 8 Ball milling technique involving the use of agate balls in a ball mill jar where the nanoparticles are milled with the polymer to produce a polymer nanocomposite

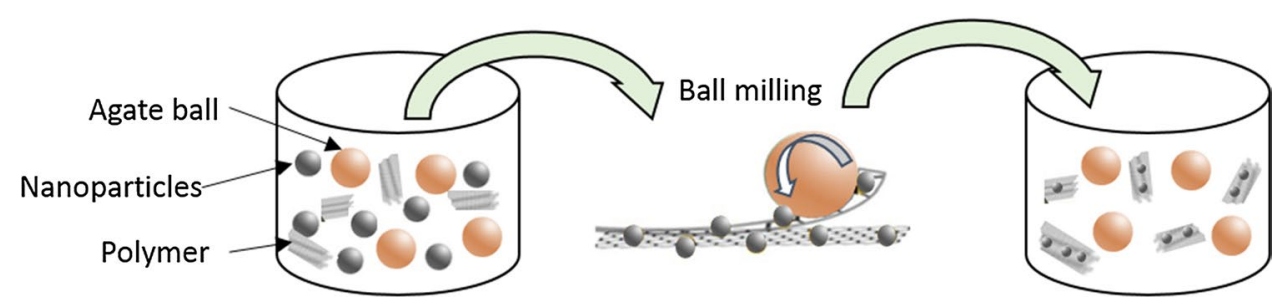




\section{Polymer composites for gamma-radiation shielding}

\section{Development of polymer composites as gamma-radiation shielding materials}

To improve the polymer performance and characteristics, a stiff material called filler can be added to the polymer matrix to form a polymer composite. The combination between filler and polymer matrix provokes the formation of a mixture that influences the polymer-composite properties by retaining the properties of both the filler and the polymer. The composite materials are named according to the reinforcement and the matrix material constituting them. There are many types of matrix materials such as metal matrix composites, polymer matrix composites, ceramic matrix composites, and epoxy resin matrix composites. The availability of radiation shielding materials that can be moulded into specific shapes and used even at high temperatures is quite significant for medical and industrial procedures.

The resistance of a material to radiation is attributed to many factors such as the type of radiation used, the rate of absorbed dose, radiation exposure (pulsed or continuous), area and size of the material, the surrounding environment (pressure, temperature, electric, or magnetic field) (McMillan 2019). But in inorganic materials, the radiation resistance depends on the type of chemical bond and crystal structure of the material (Wozniak et al. 2017). Due to relatively high processing ability and durability, polymer composite materials are vastly used in various fields of industry. Since 1916, the first polymer composite was used as phenol-formaldehyde resin (wood flour) by bakelite. Recently, about 10,000 fillers are known and used. The main duty of the filler is to provide the material with special properties and costeffectiveness. Composites of polymer materials are superior due to their merits in flexibility, low cost, workability, mechanical stability, high aspect ratio. Also, the research studies confirmed that composite materials not only are better in radiation resistance but also have thermal stability and high mechanical properties (Zezin et al. 2004). Numerous studies are reporting the use of polymer composites as gamma-radiation shields.

Different barite concentrations $0 \%, 10 \%, 20 \%, 30 \%, 40 \%$, and $50 \%$ were added to epoxy, and the linear attenuation coefficients of the composites increased with the increase in barite concentrations (Al-Sarray et al. 2017). Styrenebutadiene rubber (SBR-1502)/montmorillonite nanocomposites in the presence of ferric oxide $\left(\mathrm{Fe}_{2} \mathrm{O}_{3}\right)$, zinc oxide $(\mathrm{ZnO})$, molybdenum oxide $(\mathrm{MoO})$, and titanium dioxide $\left(\mathrm{TiO}_{2}\right)$ were synthesized to investigate their effectiveness in shielding against gamma radiation. Styrene-butadiene rubber/molybdenum oxide (SBR/MoO) composite confirmed the best performance as a radiation shield and its effectiveness in nuclear medicine departments (Atta et al. 2015). The gamma-rays radiation shielding properties for composites of natural rubber (NR) and styrene-butadiene rubber (SBR-1502) incorporated with different concentrations of the lead were investigated by using ${ }^{137} \mathrm{Cs}$ as a gamma radiation source. The results confirmed that the linear attenuation coefficient $\mu$ increased significantly with the increase in filler content (Gwaily 2002). Multiple ABS (acrylonitrile butadiene styrene) with different addition concentrations of bismuth $\left(1.2-2.7 \mathrm{~g} / \mathrm{cm}^{3}\right)$ was synthesized and tested, and the radiation attenuation behavior was improved by increasing bismuth concentration (Ceh et al. 2017). Also, polylactic acid (PLA) nanocomposites containing 3\%, 5\%, and 7\% zeolite were prepared by solution casting method. The increment in zeolite content promoted the increase in radiation resistance due to polymer interaction with radiation and the formation of reactive (Yildirim and Oral 2018). Gamma-ray shielding performance of 3-dimensional (3D)-printed polyether-ether-ketone/tungsten composites (Wu et al. 2020) and poly(vinyl alcohol)-bismuth oxide composites (Muthamma et al. 2019) for X-ray and gamma $(\gamma)$-ray shielding applications were investigated.

Polycarbonate (PC) loaded with different filler levels equal to $0.1,0.2,0.3,0.5,0.75,1.0,2.5,3.5$, and $5.0 \mathrm{wt} \%$ (weight percent) of bismuth nitrate pentahydrate $\left(\mathrm{Bi}\left(\mathrm{NO}_{3}\right)_{3} \cdot 5 \mathrm{H}_{2} \mathrm{O}\right.$ or $\left.\mathrm{BNP}\right)$ was prepared via dispersing of filler in polycarbonate solution, followed by casting. The radiation attenuation parameters showed considerable variation with a strong dependence on the energy of the incident gamma-ray photon and the concentration of bismuth nitrate pentahydrate (BNP) incorporated as filler within the polycarbonate matrix (Mirji and Lobo 2020). Gadolinium oxide/ poly-ether-ether-ketone $\left(\mathrm{Gd}_{2} \mathrm{O}_{3}\right.$ /PEEK) composites were synthesized using a twin-screw extruder. The $\mathrm{X}$-ray shielding properties of composites improved with the increment of the $\mathrm{Gd}_{2} \mathrm{O}_{3}$ (gadolinium oxide) (Wang et al. 2015). Polyethylene/boron carbide composites were fabricated using conventional polymer processing techniques. The sample containing $2 \mathrm{wt} \%$ (weight percent) boron carbide composite showed the best radiation shielding measurements (Harrison et al. 2008). Photon shielding properties for bismuth oxychloride ( $\mathrm{BiClO}) 5,10,15$, and $20 \%$ filled polyester concretes were studied in the energy range of 59.5-1408 keV using an HPGe detector. The experimental values are in good agreement with those obtained from XCOM and FLUKA code. In the prepared polymer composites, bismuth oxychloride $(20 \%)$ filled polyester has the best radiation shielding property among the selected samples (Sharma et al. 2020). Gamma-ray and neutron shielding characteristics of polypropylene fiber-reinforced heavyweight concrete exposed to high temperatures were studied and barite concrete for simultaneously achieving better residual compressive 
strength, gamma ray, and neutron shielding capability were recommended (Demir et al. 2020).

Four samples have been prepared by different proportions (5-20\%) of filler materials (barium titanate, $\mathrm{BaTiO}_{3}$, and calcium tungsten oxide, $\mathrm{CaWO}_{4}$ ). Experimentally determined values of the linear attenuation coefficients, radiation protection efficiencies, half-value layers, mean free paths, and effective atomic numbers of studied polymer composites have been supported with theoretical results. Among the prepared polymer composites, barium titanate $(20 \%)$ and calcium tungsten oxide (20\%) have better gamma-ray attenuation characteristics than the other tested polymer composites. Calcium tungsten oxide, $\mathrm{CaWO}_{4}(20 \%)$, has slightly better gamma-ray attenuation properties than barium titanate, $\mathrm{BaTiO}_{3}$ (20\%) (Akman et al. 2020). Gamma-ray attenuation characteristics of poly (methyl methacrylate) composites with $0-44 \mathrm{wt} \%$ of bismuth trioxide $\left(\mathrm{Bi}_{2} \mathrm{O}_{3}\right)$ filler were investigated. The fast ultraviolet curing method was used for the preparation of polymer composites. The physical and mechanical properties of prepared polymer composites have also been studied. The high loading of bismuth trioxide in the polymethyl methacrylate (PMMA) samples improved the microhardness to nearly seven times that of the pure PMMA (polymethyl methacrylate) (Cao et al. 2020). Using NaI detector for gamma rays detection, the attenuation parameters of including the mass attenuation coefficient $(\mu / \rho)$, mean atomic number $(<Z>)$, effective atomic cross section $\left(\sigma_{\mathrm{a}}\right)$, effective atomic number $\left(Z_{\text {eff }}\right)$ plus electron number $\left(N_{\text {eff }}\right)$ for the samples: pure epoxy, aluminum oxide $\left(\mathrm{Al}_{2} \mathrm{O}_{3}\right)$ epoxy ( 6 and 15 weight \%), and ferric oxide $\left(\mathrm{Fe}_{2} \mathrm{O}_{3}\right)$ epoxy/ (6 and 15 weight \%), were determined. With the increase in gamma-ray energy, mass attenuation coefficient and effective atomic cross-section values were decreased, whereas effective atomic and electron number values were increased (Al-Dhuhaibat et al. 2020).

Gamma-ray shielding properties of polyester composite reinforced with different proportions of cadmium telluride (CdTe) have been investigated experimentally using HPGe detector and theoretically using XCOM program in the energy range of 59.5-1408.0 keV. Remarkable radiation protection efficiency was obtained by filler material cadmium telluride (Akman et al. 2021). Photon attenuation characteristics such as mass attenuation coefficient, half and tenth value layer, mean free path, effective atomic number and electron density, and buildup factors of polyvinyl alcohol (PVA) mixed with lead nitrate, $\mathrm{Pb}\left(\mathrm{NO}_{3}\right)_{2}(0-30$ weight $\%)$ were studied experimentally along with using XCOM values and MCNP5 simulations. With the increase in additive material, radiation shielding characteristics of polymer matrix were observed to be increased (Issa et al. 2019). A skininteractive metal-free spongy electrode in the piezoelectric sensor was reported where highly aligned poly(vinylidene fluoride) (PVDF) nanofibers (NFs) arrays are introduced as piezoelectric active component and conducting polyanilinecoated polyvinylidene difluoride (PANI-PVDF) nanofibers mats served as flexible electrodes. Ninety-nine percent yield of piezoelectric phases of the aligned polyvinylidene difluoride arrays is the key factor to exhibit promising mechano-sensitivity performance that in turn helps in human health monitoring (Maity et al. 2020). The radiation shielding properties of flexible polyvinyl alcohol/iron oxide polymer composite with five different concentrations of magnetite were investigated in the energy range of $15 \mathrm{keV}-20 \mathrm{meV}$. $0.5 \%$ of the magnetite which gives superior shielding properties compared with other concentrations (Srinivasan and Samuel 2017).

For filler-enhanced materials, innovation has led to greatly improved properties and functions with nanofillers, which cannot be obtained using traditional macro- and microtechnology within normal filler loading levels. Fillerenhanced polymer nanocomposite technology is one of the driving forces in stimulating and promoting nanotechnology development and has attracted considerable interest in both academia and industry. At present, nanotechnology has expanded into almost every aspect of science and technology.

\section{Advances in polymer composites by the use of nanofillers}

In general, the incorporation of nanofillers into the composite material leads to the enhancement of composite properties. The filler is bonded to the polymer matrix via weak chemical and intermolecular forces. But on the nanometer scale, a nanofiller can be dispersed within the polymer matrix. Thus, the molecular interactions between the matrix and the filler are improved via chemical bonding leading to further enhancement in the mechanical and physical properties of the new polymer nanocomposites (Kumar et al. 2009). The nanofillers are characterized by a high surfaceto-volume ratio which causes the alteration in the macromolecular state around the nanoparticles. Promising features of the polymer are enhanced by the addition of nanofiller, such as increased elastic stiffness and strength, heat and barrier resistance, decreased gas permeability, and mainly radiation resistance. Also, nanoparticles offer a great advantage compared to other additives to the polymer since the loading requirements are quite low. Many factors can influence polymer nanocomposites including the type of filler, the ratio of the filler to matrix, synthesis technique, and its conditions. By dispersing nanofillers within a polymer matrix, an obvious enhancement in the composite properties is obtained.

Many polymers can be added as the base matrix, and polyethylene (PE) as an example is a widely used material in many applications; however, many environmental factors affect this polymer such as solar radiation, 


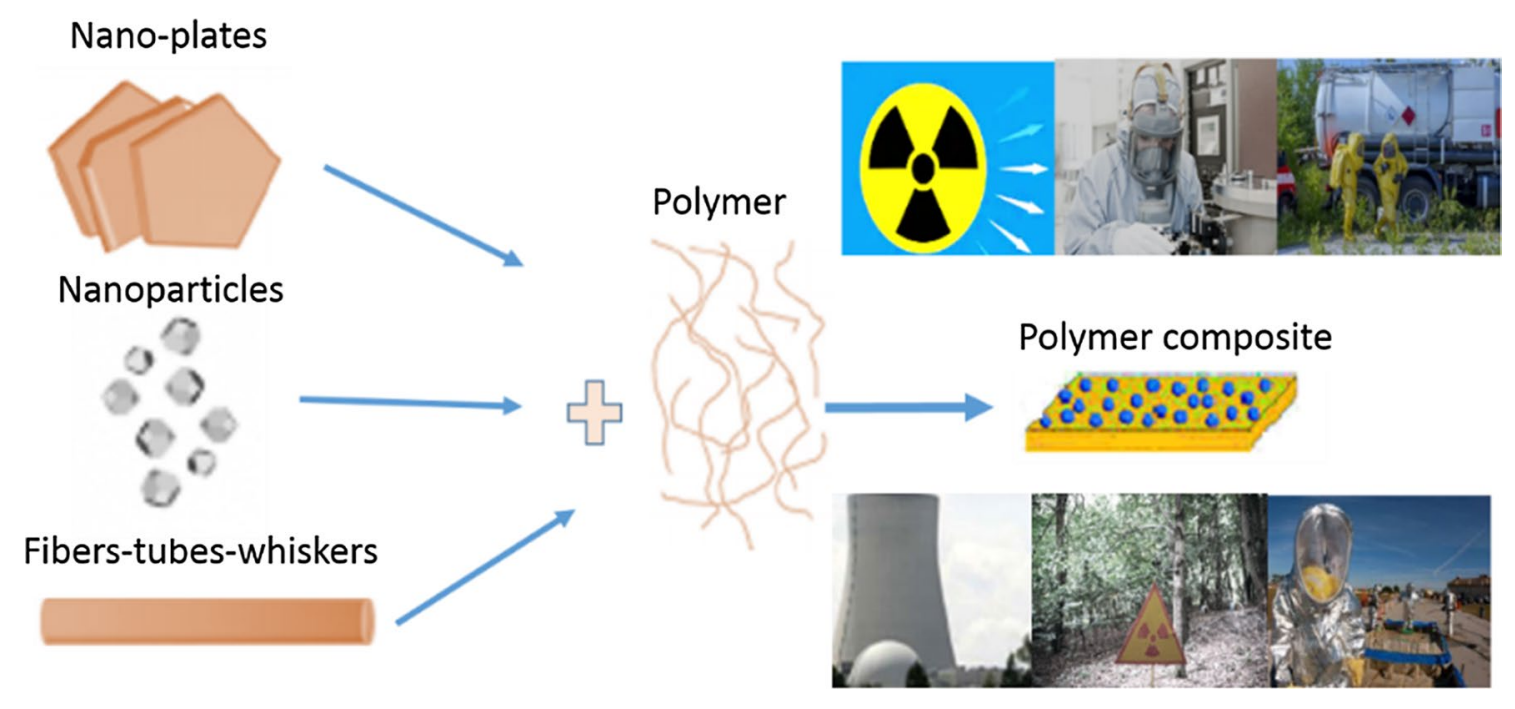

Fig. 9 Many forms of nanoplates, nanoparticles, fibers, tubes, and whiskers can be added to polymer matrix to synthesize polymer composites which can be used as radiation shielding materials in radiation facilities, nuclear power plants, and also nuclear cleaning of environment

temperature, thermal cycling, humidity, weather, and pollutants. Other types of polymers such as low-density polyethylene (LDPE), high-density polyethylene (HDPE), polyvinyl alcohol (PVA), polystyrene (PS), polypropylene (PP), and polyvinyl pyrrolidone (PVP) are also important and widely used. An important feature that characterizes polymer nanocomposites is their good performance in radiation shielding. Protection and convenient shielding against ionizing radiation are essential to minimize the harmless effect on both humans and the environment. As illustrated in Fig. 9, many forms of nanoplates, nanoparticles, fibers, tubes, and whiskers can be added to polymer matrix to synthesize polymer composites which can be used as radiation shielding materials in radiation facilities, nuclear power plants, and also nuclear cleaning of environment. Various studies focused on the effect of adding nanofiller on the radiation shielding behavior of polymer composites. The incorporation of different types of fillers into the polymer matrices has shown interesting results in the attenuation of gamma radiation.

The incorporation of nanofillers mainly carbon-based and metal/metal oxide nanoparticles into polymeric membrane matrixes improved the filtration capability of nanocomposite membranes to separate pollutants from water which has been a global challenge due to the great demand for clean water supply (Wen et al. 2019). The degradation of fragmented microplastic residues containing low-density polyethylene (LDPE) via visible-light-induced heterogeneous photocatalysis enhanced by zinc oxide nanorods showed an increase in brittleness, cracks on the surface, and in carbonyl index of residues with a value of $30 \%$ (Tofa et al. 2019). High-density polyethylene (HDPE) composite loaded with tungsten $(\mathrm{W})$, molybdenum disulfide $\left(\mathrm{MoS}_{2}\right)$, and boron carbide $\left(\mathrm{B}_{4} \mathrm{C}\right)$ demonstrated that the flexible composite sheet of high-density polyethylene/45\% (wt) tungsten provided comparable X-ray absorption to the non-flexible lead sheet but much lighter in weight (Afshar et al. 2019). Micro- and nanosized tungsten oxide $\left(\mathrm{WO}_{3}\right)$ were added to polyvinyl chloride (PVC) and studied against low energy X-rays, and nanostructured tungsten oxide/polyvinyl chloride shields have higher photon attenuation compared to the microsized samples (Aghaz et al. 2016). Cerium oxide $\left(\mathrm{CeO}_{2}\right)$ nanoparticles were synthesized by the solgel method and were further used to develop polysulfone-cerium oxide mixedmatrix membrane with enhanced gamma radiation-resistant property (Bedar et al. 2019).

The gamma-ray attenuation parameters of high-density polyethylene/zinc oxide composite prepared via compression moulding technique by mixing bulk and nanozinc oxide of weight percent $(10,20,30$, and 40 weight $\%)$ with high-density polyethylene as a polymer matrix were studied. The results obtained for radiation shielding parameters of nanozinc oxide blended with high-density polyethylene were found to be more promising and efficient for radiation protection against gamma-ray. Mass attenuation coefficient, molecular, and atomic cross-section $\left(\mu_{\mathrm{m}}, \sigma_{\mathrm{mol}}\right.$, and $\left.\sigma_{\mathrm{atm}}\right)$ values decreased with incident photon energy and increased with the weight percentage of both bulk and nanozinc oxide filler (Alsayed et al. 2019, 2020). Epoxy composite samples filled with lead oxide $(\mathrm{PbO})$ and lead tetraoxide $\left(\mathrm{Pb}_{3} \mathrm{O}_{4}\right)$ were fabricated to investigate the mass attenuation characteristics of the composites to X-rays in the diagnostic imaging energy range. The effect of density on the attenuation ability of the composites for radiation shielding purposes was studied using a calibrated X-ray machine (Azman et al. 2013). By varying the amounts of powdered fillers 
lead oxide $(\mathrm{PbO})$ and tungsten oxide $\left(\mathrm{WO}_{3}\right)$ added to low density-polyethylene, the attenuation performance against gamma radiation was studied revealing that the samples of high filler loadings showed good attenuation performance against gamma radiation (Belgin and Aycik 2015). Also, zirconium dioxide $\left(\mathrm{ZrO}_{2}\right)$ nanoparticles with various weight percent $(1,2,3,5$, and $10 \mathrm{wt} \%)$ were added to synthesize poly(vinylidene fluoride-tryfluorethylene)/zirconium dioxide $\left[\mathrm{P}(\mathrm{VDF}-\mathrm{TrFE}) / \mathrm{ZrO}_{2}\right]$ polymer composites and investigate their protective shielding of patients during radiological procedures (Fontainha et al. 2016).

Ultra-high-molecular-weight polyethylene (UHMWPE) fiber epoxy composite hybridized with gadolinium, boron nanoparticles (Mani et al. 2016), and nanoepoxy (Zhong et al. 2009) showed good neutron shielding performance. Moreover, high-density polyethylene/bismuth (HDPE/Bi) composite prepared by adding different weight percentages $(0 \%, 10 \%, 20 \%$, and $40 \%)$ of bismuth in high-density polyethylene (HDPE) matrix showed the shielding efficiency of synthesized high-density polyethylene/bismuth composites increases with an increase in the weight percentage of bismuth (Sheela et al. 2019). The physicochemical properties of low-density polyethylene and ethylene-vinyl acetate composites cross-linked by ionizing radiation by melt mixing showed that low-density polyethylene/ethylene-vinyl acetate copolymer/carbon black (LDPE/EVA/CB) and ethylene-vinyl acetate copolymer/carbon black (EVA/ CB) composites tend to crosslink by irradiation (Basfar and Ali 2011). Using Ba-133, Cs-137, and Co-60 gamma-ray sources, the effect of adding bismuth oxide as a reinforcement to unsaturated polyester was investigated, revealing that by increasing filler content, the radiation shielding properties increase. The half and tenth value layer and relaxation length of the composites were found to decrease with an increase in the filler concentration (Ambika et al. 2017). Nanotungsten (W) dispersed polymer composite was significant $75 \%$ for $133 \mathrm{Ba}(\approx 0.3 \mathrm{meV})$ compared to the microtungsten (W) composites (Das et al. 2009), and also silicone rubber matrix dispersed with $37.5 \%$ weight of tungsten (W) and bismuth oxide $\left(\mathrm{Bi}_{2} \mathrm{O}_{3}\right)$ confirmed good gamma-ray-shielding performance compared to lead (Atashi et al. 2018). Tungsten oxide $\left(\mathrm{WO}_{3}\right)$ and bismuth oxide $\left(\mathrm{Bi}_{2} \mathrm{O}_{3}\right)$ nanoparticles improved the radiation shielding properties of hematite-serpentine concrete (HSC) (Tekin and Issa 2018) and emulsion polyvinyl chloride (EPVC) (Shik and Gholamzadeh 2018).

The effect of adding lead $(\mathrm{Pb})$ powder to natural rubber (NR) and wood/natural rubber composites was investigated, and their performance in radiation shielding was efficient in attenuating low-intensity gamma rays (Ninyong et al. 2019). Iso-phthalate-based unsaturated polyester resin filled with different concentrations of lead monoxide particulate polymer composites was prepared for gamma rays of energy $0.662 \mathrm{meV}$ from ${ }^{137} \mathrm{Cs}$ point source, and linear attenuation coefficient was found to increase with increased filler content in the composites (Harish et al. 2012). The radiation shielding properties of concrete were improved for gamma rays of 662, 1173 , and $1332 \mathrm{keV}$ using ${ }^{137} \mathrm{Cs}$ and ${ }^{60} \mathrm{Co}$ sources via adding nano lead compounds (Hassan et al. 2015). Nanogadolinium oxide $\left(\mathrm{Gd}_{2} \mathrm{O}_{3}\right)$ composites were more efficient in shielding $\mathrm{X}$ - and gamma ray than microgadolinium oxide $\left(\mathrm{Gd}_{2} \mathrm{O}_{3}\right)$ composites, and an enhanced effect of $\sim 28 \%$ was obtained with gadolinium oxide $\left(\mathrm{Gd}_{2} \mathrm{O}_{3}\right)$ content of around 5 weight percent at $59.5 \mathrm{keV}$ (Li et al. 2017). The addition of micro- and nanocadmium oxide $(\mathrm{CdO})$ particles to the high-density polyethylene matrix increased the mass attenuation coefficients of the composites mainly at low gammaray energies (El-Khatib et al. 2019). The polymer-matrix composites based on high-density polyethylene with either lead oxide $(\mathrm{PbO})$ nanoparticles or lead oxide bulk using 10 and $50 \%$ weight fractions synthesized by solid-state intermixing and thermal pressing technique showed interesting gamma-rays shielding properties especially for high filler loadings (Mahmoud et al. 2018a, b).

$\mathrm{X}$ - and gamma-rays attenuation parameters for polyacrylamide and zinc oxide ( $\mathrm{ZnO})$ composites were evaluated as light-shielding materials using MCNP and XCOM simulation. The obtained results showed that the composites were better in gamma-ray shielding performance compared to the bulk of zinc oxide (Nasehi and Ismail 2019). Extensive investigation on gamma-ray shielding features of palladium/silver $(\mathrm{Pd} / \mathrm{Ag})$-based alloys in the energy range $81 \mathrm{keV}-1333 \mathrm{keV}$ by using an HPGe detector, revealing that palladium/silver ( $\operatorname{Pd} 75 / \mathrm{Ag} 25)$ alloy sample had superior photon shielding characteristics among all composites (Agar et al. 2019). Unsaturated polyester containing 5 weight percent nanoclay and different amounts of lead monoxide particles $(0,10,20$, and 30 weight percent) were investigated by ${ }^{192} \mathrm{Ir},{ }^{137} \mathrm{Cs}$, and ${ }^{60} \mathrm{Co}$ gamma radiation sources, the mass, and linear attenuation coefficients which were increased by increasing lead monoxide content (Bagheri et al. 2018). The radiation shielding performance of natural fiber high-density polyethylene and lead oxide composites revealed that the mass attenuation value decreased sharply from $10 \mathrm{keV}$ to $0.8 \mathrm{meV}$ and then smoothly decrease above 0.8 up to $15 \mathrm{MeV}$ (Abdo et al. 2003). Nanostructured natural bentonite clay coated by polyvinyl alcohol polymer materials (Hager et al. 2019) were developed for gamma rays attenuation.

The radiological parameters of composite filler, zirconium, and acrylic coating materials used in dental treatment revealed that maximum attenuation occurred for samples of $1 \mathrm{~mm}$ thickness where $21 \%, 10 \%$, and $2 \%$ of the incident radiation were absorbed by zirconium, composite, and acrylic samples, respectively (Abbasova et al. 2019). The attenuation coefficients against gamma radiation were studied for polyvinyl alcohol-polyethylene glycol-polyvinyl pyrrolidinone with zirconium oxide (PVA-PEG-PVP-ZrO ${ }_{2}$ ) 
nanocomposites which showed to increase with zirconium oxide content (Agool et al. 2017). Also, tungsten/bismuth oxide/methyl vinyl silicone rubber (W/Bi2O3/VMQ) composites exhibited higher $\mathrm{X}$-ray-shielding properties in the $\mathrm{X}$-ray energy ranging from 48 to $185 \mathrm{keV}$ (Chai et al. 2016). Ultra-high-molecular-weight polyethylene (UHMWPE) with boron carbide, $\mathrm{B}_{4} \mathrm{C}$, and tungsten, $\mathrm{W}$, nanopowders were fabricated by solid-state intermixing and thermal pressing, and the gamma protection properties increased with tungsten content in the composite (Kaloshkin et al. 2012). Polymer composites with different aluminum oxide percentages $(x=0,10,20,30,40$, and 50 weight percent $)$ were prepared, and the composites of 40 weight percent (wt\%) aluminum oxide $\left(\mathrm{Al}_{2} \mathrm{O}_{3}\right)$ revealed the highest values of radiation attenuation (Osman et al. 2015). Bismuth nanoparticles with cellulose nanofibers and polydimethylsiloxane (PDMS) polymer can effectively shield X-ray radiation at a lower mass ratio in the polymer matrix (Li et al. 2018). Novel polyvinyl alcohol (PVA)/tungsten oxide $\left(\mathrm{WO}_{3}\right)$ composite consisting tungsten oxide $\left(\mathrm{WO}_{3}\right)$ at sizes of $10 \mu \mathrm{m}$ and $30 \mathrm{~nm}$ with a weight concentration of 50 weight \% was studied for gamma-ray shielding (Kazemi et al. 2019).

The polyacrylamide (PAGAT) gel and metal nanoparticle (different concentrations of gold and silver) verified the water equivalency based on an effective atomic number (Sathiyaraj et al. 2017). Different percentages of tungsten carbide (50,60, and 70\%) were added and tested against gamma radiation $\left({ }^{137} \mathrm{Cs}\right.$ and ${ }^{131} \mathrm{I}$ and $\left.{ }^{241} \mathrm{Am}\right)$, and the best shielding efficiency against gamma radiation was revealed by the composite with $70 \%$ tungsten carbide (WC) (Soylu et al. 2015). Different percentages of tungsten carbide (50, 60 , and $70 \%$ ) were added and tested against gamma radiation $\left({ }^{137} \mathrm{Cs}\right.$ and ${ }^{131} \mathrm{I}$ and $\left.{ }^{241} \mathrm{Am}\right)$, the best shielding efficiency against gamma radiation was revealed by the composite with 70\% tungsten carbide (Özdemir et al. 2018). Graphite/epoxy composite showed the highest performance in gamma radiation attenuation among epoxy/graphite, epoxy/ lead, and epoxy/boron (Saiyad et al. 2014). A proportional relationship between photon attenuation coefficients and barite concentration was revealed when barite and boron carbide-doped radiation shielding polymer composite was prepared for radiation shielding (Evcın et al. 2017). Blended powdered polyethylene glycol and lead oxide prepared by physical mixing revealed that the shielding properties of polyethylene glycol increased with the addition of lead oxide (Hussain et al. 1997).

The influence of bismuth contents on mechanical and gamma-ray attenuation properties of silicone rubber composite was studied, showing that the increase in bismuth content induced an increase in radiation shielding performance (El-Fiki et al. 2015). Four different colemanite $\mathrm{Ca}_{2} \mathrm{~B}_{6} \mathrm{O}_{11} \cdot 5 \mathrm{H}_{2} \mathrm{O}(\mathrm{CMT}$ ) concentration levels (such as 5,15 , 30 , and 40 weight percent) were examined to investigate the radiation protective shielding properties of poly(methyl methacrylate)/colemanite (PMMA/CMT) composite. Colemanite reinforcement of poly(methyl methacrylate) increased the radiation shielding capacity by $11.1 \%$ for gamma photons of Cs-137 radioisotope (Bel et al. 2018). By blending epoxy resin with different weight percent of tungsten powder, tungsten/epoxy composites were prepared and investigated by using two different activities of Co-60 source showing that with the increment of tungsten loading, the shielding property of composites increased (Chang et al. 2015). Besides, ethylene-vinyl acetate (EVA)-tungsten composite (Yurt Lambrecht et al. 2016) and polyimide/ bismuth oxide (Pavlenko et al. 2019) composites revealed high radiation-protective characteristics. The shielding effect and the protective properties of the samples of aluminum alloys with a protective coating were evaluated revealing that tungsten-aluminum oxide $\left(\mathrm{W}-\mathrm{Al}_{2} \mathrm{O}_{3}\right)$ and tungsten-boron nitride (W-BN) coatings contribute significantly to the attenuation of ionizing radiation fluxes (Vilkov et al. 2017). Poly (lactic acid) (PLA) nanocomposites containing $3 \%, 5 \%$, and $7 \%$ zeolite were prepared and investigated against gamma radiation at the absorbed doses of 10,15 , and $20 \mathrm{kGy}$. The results revealed that increasing zeolite content in the structure promoted the recombination of the reactive species formation with the interaction of the radiation in the polymer and increased the radiation resistance (Yildirim and Oral 2018).

Silica nanoparticles combined with composites are widely used for various applications (Soundharraj et al. 2020) such as glucose biosensors when combined with gold nanoparticles to form mesoporous silica composite, by incorporating silica nanoparticles to carbon dots for bioimaging applications, in drug delivery when mesoporous mobil composition of matter (MCM)-41-silica is loaded with ibuprofen, monodispersed silica with uniform hollow-core mesoporous shell carbon nanospheres for supercapacitor applications. Different types of metal and metal oxide nanoparticles including silver, copper, palladium, zinc oxide, magnesium oxide, tin oxide are synthesized with various polymers and used for antimicrobial activity, food packaging, and improving shelflife of food (Rai et al. 2018). Carbon-based nanostructures such as semiconductor compounds and polyoxometalates are used for water purification (Lopes et al. 2021).

\section{Recycling of polymers}

Materials that have reached their end of life after primary use or of no use must be dismissed, and materials that remain from production are considered waste. Plastic waste is a part of this term. The primary constituents of municipal, industrial, and agricultural plastic wastes are generally thermoplastics because of the large volume and low cost of these materials such as high-density polyethylene, 
polypropylene, ethylene-propylene copolymer, polystyrene, low-density polyethylene, polyamide, polyethylene terephthalate, polyvinyl chloride, and these thermoplastics can be recycled. Besides, it consists of small amounts of thermosets like epoxy resins and polyurethane rubber and these thermoset plastics cannot be recycled (Miskolczi et al. 2004). Nowadays, the Covid-19 pandemic has posed a huge plastic pollution worldwide, which lead to urgent and massive use of fossil fuel-derived plastic (Sorrentino et al. 2020).

Plastic wastes are a mixture of different types of plastics along with some contaminations. Microplastics which are considered plastic particles smaller than $5 \mathrm{~mm}$ represent slowly degrading contaminants in soil and water exposing human health and environment to toxic incorporation of these materials (Padervand et al. 2020). Also, this waste is big in volume, and for the waste management of plastic waste, an integrated waste management approach is needed. There are three ways for disposal of municipal and industrial plastic waste: incineration (with or without energy recovery), landfilling, and recycling. The incineration method for plastics wastes is always accompanied by the emission of harmful, greenhouse gases. More energy is dissipated in the process of plastic incineration. Also, landfilling is not an efficient technique because suitable and safe deposits are expensive (Grigoriadou et al. 2011). Thus, recycling is the best way to manage plastic wastes since it reduces environmental impact, resource depletion, and pollution. Besides, recycling of the plastics consumes a smaller amount of energy when compared to energy consumption in new virgin resin production. Fundamentally, high levels of recycling, as with a reduction in use, reuse, and repair or re-manufacturing can allow for a given level of product service with lower material input that would otherwise be required. Therefore, recycling can decrease energy and material used per unit of production and so yield improved eco-efficiency (Hamim et al. 2016).

Recycling can be divided into two categories: mechanical recycling and chemical recycling (Miskolczi et al. 2004). Chemical recycling is virtually a thermal method by which the long alkyl chains of polymers are broken into a mixture of lighter hydrocarbons. Several chemical reactions such as pyrolysis, cracking, glycolysis, and gasification can be used for the decomposition of polymers (Lee et al. 2002), whereas mechanical recycling is a physical method. It usually consists of contamination removal of the plastic wastes by sorting and washing, followed by grinding or conversion into flakes, granulates, or pellets, then drying, and melt processing to make the new product by extrusion. It is noted that mechanical recycling is the better method for recycling as is relatively simple, environmentally friendly, and requires low investment (Awaja and Pavel 2005).

Collection of post-consumer plastic wastes, separation, processing (manufacturing), and marketing are the four steps in plastic recycling (Shent et al. 1999). Different types of polymers need to be separated from each other from the collected plastics waste to get better quality of recycled plastic. Several techniques can be used to separate mixed plastic wastes based on their physicochemical properties such as gravity separation, contact charging, hydro-cyclones and centrifuges, and froth flotation (Pascoe 2003). The produced recycled plastic can be used to manufacture new products such as automobile parts, floor carpets, flower vases, park benches, picnic tables, waste paper baskets, crates, plastic lumber, wood-plastic composites which will provide an additional market for recycled plastics. Sustainable and lowcost radiation shielding materials can be fabricated using composite materials from post-consumer recycled thermoplastics for various applications such as space, industry, and radiation facilities as shown in Fig. 10 (Cholake et al. 2017; Mahmoud et al. 2018a, b). Massive amounts of polyethylene terephthalate, high-density polyethylene, polyvinyl chloride, low-density polyethylene, polypropylene, polystyrene, and miscellaneous plastics can be recycled to fuels via many thermomechanical technologies including pyrolysis, liquefaction, and gasification (Nanda and Berruti 2020). Cellulose nanoparticles were extracted from from conventional and nonconventional lignocellulosic biomass for food packaging applications to avoid the extensive use of nonbiodegradable materials. The synthesized cellulosic nanocomposites exhibited promising optical, biodegradation, mechanical, and barrier properties due to the large surface area of nanoscale structure (Qasim et al. 2020). Nanomaterials play also an important role in moisture absorbing packaging in food industry taking into consideration all the safety concerns and toxcitiy issues (Gaikwad et al. 2018). Cerium dioxide and composites are used as adsorbents for water decontamination to remove contaminants such as arsenic, fluoride, lead, and cadmium (Olivera et al. 2018).

\section{The use of processed and post-consumed polymers as composite materials for different applications}

The world's main focus nowadays is the use of new materials that are eco-friendly to reduce the burden of pollution via recycling these materials and enhancing their sustainability. This urged the need and synthesis of new composite materials via adding fillers as alternatives for replacing toxic and harmful fabricated materials. New attempts to process and refine post-consumed polymers are obtained. Many researchers are concerned about the use and processing of composite materials for various types of applications.

Iron-based magnetic (Marcelo et al. 2020) and silver-magnetic nanocomposites (Surendhiran et al. 2017) are of great importance as they display promising performance in removing pollutants from water, adsorption of heavy metal ions, photocatalysis, soil conditioning (Sharma et al. 2018), and many other applications such as optical 


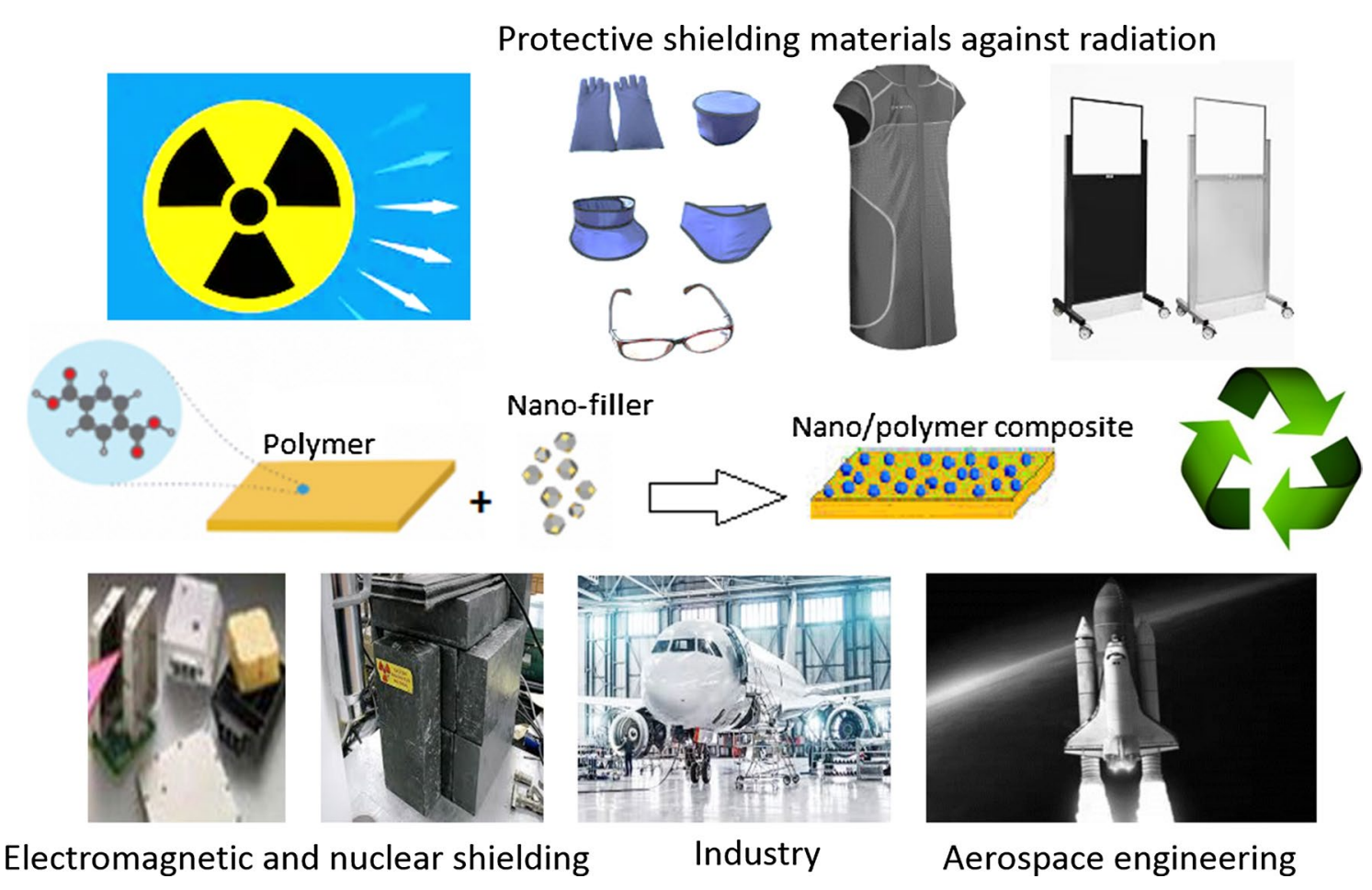

Fig. 10 Use of polymer composite materials after recycling in various applications such as protective shielding materials in radiation facilities, aerospace engineering, industry, electromagnetic, and nuclear shielding

application, hydrogen storage, magnetic resonance imaging,, and cancer diagnosis (Siddiqui et al. 2018). Also, the use of thermosets, fabrics, and textiles-based materials as polymer matrices has been extensively reported and investigated. Conversion of waste-derived high-density polyethylene to three-dimensional (3D) printing filament has important technological implications. A facile strategy to expand the palette of waste-derived polymer materials for fused filament fabrication (FFF) three-dimensional (3D) printing was explained in details (Gudadhe et al. 2019). The polymer-matrix composites based on recycled high-density polyethylene with either lead oxide nanoparticles or lead oxide bulk using 10 and $50 \%$ weight fractions were synthesized by solid-state intermixing and thermal pressing technique. This study suggests that the recycled high-density polyethylene/lead oxide nanocomposites could be used as sustainable gamma-radiation shields and these composites of the recycled polymer are environmentally effective (Mahmoud et al. 2018a, b).

Banana/E-glass fabrics fabricated by reinforcing polyester hybrid composites were evaluated. The maximum hardness and tensile strength were attributed to pure glass fabric laminate, whereas minimum values were attributed to pure banana fabric laminate. The mechanical properties of the synthesized materials were enhanced by the addition of the glass layer. The maximum absorption of water was established by pure E (electrical)-glass fabric laminate
(Sanjay et al. 2016). The performance of polyurethane-based composites prepared from recycled polymer concrete via adding ethylene-vinyl acetate (EVA) was investigated, the mechanical and durability of the composite were enhanced by increasing ethylene-vinyl acetate content. The performance of polyurethane-based composites is prepared from recycled polymer concrete via adding ethylene-vinyl acetate (EVA). They found that the mechanical and durability of the composite were enhanced by increasing ethylene-vinyl acetate (Ma et al. 2020). A combination of recycled polyethylene terephthalate (PET) fibers and epoxy/calcium carbonate $\left(\mathrm{CaCO}_{3}\right)$-stearic acid composites was prepared, the optimal content for calcium carbonate $\left(\mathrm{CaCO}_{3}\right)$ particle modification was $2 \mathrm{wt} \%$ (weight percent), and the thermal stability and mechanical properties were improved (Nguyen et al. 2020). Different wt\% (weight percent) of coal mining waste (CMW) were added to synthesize coal mining waste/lowdensity polyethylene (CMW/LDPE) composite and study the eco-toxicological effects in water and soil. The results confirmed that a 50\% increment in the $\mathrm{pH}$ value was for the leachate of $20 \%$ weight low density polyethylene composite with a noticeable reduction in the eco-toxicological effect (Gryczak et al. 2020).

The recycled filaments of continuous carbon fiber and polylactic acid (PLA) matrix showed a high tensile performance with high bending strength. Due to the special properties of three-dimensional printed carbon fiber-reinforced 
thermoplastic composites (CFRTPCs), high material recovery rates were observed for the polylactic acid matrix (73\%) and carbon fiber (100\%) (Tian et al. 2016). Recycled polyethylene terephthalate and polyacrylonitrile (RPET/PAN) composites showed a flexural strength increment and drying shrinkage (Chinchillas-Chinchillas et al. 2019). The chemical oxygen demand (COD) was reduced, and the mineralization percentage in recycled polymeric materials include cotton, cotton lycra, polyamide, paper, polyethylene terephthalate, polypropylene, and polyurethane (El-Mekkawi et al. 2019). The incorporation of phosphate tailings (PT) and fly ash (FA) reduced the thermal degradation temperature, smoke production rate (SPR), total heat release (THR), and the emissions of toxic carbon dioxide $\left(\mathrm{CO}_{2}\right)$ and carbon monoxide (CO) in thermoplastic polyurethane (TPU) to fabricate polymer materials having minimal fire hazards via the solvent blending method (Zhou et al. 2020). Compared to sodium silicate-concrete waste $\left(\mathrm{Na}_{2} \mathrm{SiO}_{3}-\mathrm{CoW}\right)$, the addition of 10 weight percent lead-bearing sludge (LBS) in sodium hydroxide-concrete waste $(\mathrm{NaOH}-\mathrm{CoW})$ enhanced the mechanical properties of concrete waste (CoW) (AbdelGawwad et al. 2020). Maximum water absorption was attained by the high contents of recycled newspaper fiber (RNF) composites. The incorporation of metaled polypropylene (MAPP) had an interesting effect on enhancing the adhesion quality between fibers and polymers (Ashori and Sheshmani 2010).

Maleic anhydride-modified polypropylene/desulfuration modified recycled rubber (M-PP/M-RR) revealed an important increase in the mechanical properties compared to recycled rubber (RR) (Chiang et al. 2020). Also, the addition of silicon dioxide $\left(\mathrm{SiO}_{2}\right)$ improved the mechanical properties of polyethylene terephthalate/poly(acrylonitrile butadiene styrene) (PET/ABS (Shi et al. 2011). The interfacial compatibility between high-density polyethylene and wood flour via incorporation of metaled polypropylene (MAPP) as well as flexural strength and stiffness was improved (Adhikary et al. 2008). Also, by increasing fiber loading of microcrystalline cellulose (MCC) from (2-50 weight \%), the tensile strength of recycled polypropylene/microcrystalline cellulose (PP/ MCC) composites decreased, with an increase in young's modulus (Zulkifli et al. 2015). Moreover, by increasing fiber loading (0-15 weight \%), enhancement in the tensile strength of recycled polyethylene terephthalate (RPET)/ maleic anhydride-grafted poly styrene-ethylene-butadienestyrene) (SEBS-g-MA)/date palm leaf fiber composite was observed (Dehghani et al. 2013). Also, by increasing bamboo fiber content in the recycled talc-filled polypropylene/ ethylene-propylene-diene monomer (EPDM) (Inacio et al. 2017) and due to the addition of talc in recycled polyethylene terephthalate/basalt fiber composite (Kráčalík et al. 2008), the flexural strength, tensile strength, and fatigue of composites increased. Due to the addition of graphite, mica, and talc, the impact strength of kenaf wood recycled polyethylene was enhanced as well as the glass transition temperature of recycled plastic composite, WrPC (Ramli et al. 2018).

By increasing silica nanoparticles content to 1.0 weight $\%$, the tensile properties increased and then decreased above this value. The highest obtained values of elongation at break, tensile modulus, and stress at break were revealed by unsaturated polyester resin (UPR)/vinyl silane silica nanocomposite (Rusmirović et al. 2016). The depolymerization process was used to recycled polyethylene terephthalate/dipropylene triethylene glycol and fabricate unsaturated polyester resin (UPR). The mechanical behavior of the composite after adding various wt $\%$ of graphite powder (GP 10 weight $\%$ ), $\mathrm{TiO}_{2}$ (10 weight $\%$ ), and modified clay CLOISITE 30B revealed that by addition of graphite powder or titanium dioxide $\left(\mathrm{TiO}_{2}\right)$, the composite showed better tensile properties (Marinkovic et al. 2013). By incorporating O-hydroxybenzene diazonium chloride (OBDC), silane, and glycidyl methacrylate (GMA) in sisal fiber-reinforced recycled polypropylene composites, the mechanical properties of the composite were preferably enhanced by O-hydroxybenzene diazonium chloride (OBDC)/recycled polypropylene composites (Gupta et al. 2014). Various amounts of clay content (Cloisite 10A 1 to 6 weight \%) were added to recycled polyethylene terephthalate/clay nanocomposites. Impact strength remained intact up to 4 weight $\%$ and then decreased at 6 weight $\%$ and tensile properties were increased (Chowreddy et al. 2019). Alphazirconium hydrogen phosphate $(\mathrm{ZrP})$ with the aid of chemically inert polymer coated with a titanium platinum electrode was used to collect harmful cobalt ions which are used as primary coolant in a nuclear power plant (Rathi and Ponnusamy 2020).

\section{Polymers for neutron shielding}

It is infamous that the light atoms such as hydrogenous materials are more effective at shielding fast and intermediate neutrons for their competency of neutron moderation as light atoms slow down the neutrons through elastic scattering. Thus, water is preferred for neutron shielding. But it has the drawback of being in a liquid state at room temperature. Thus, polymer materials have a greater chance of shielding neutrons. The fast neutron removal cross section $\left(\mathrm{cm}^{-1}\right)$ is the important characteristics to decide the fast neutron shielding capabilities of a material and is defined as the probability that a fast or fission energy neutron undergoes a first collision, which removes it from the group of penetrating, un-collided neutrons (Blizard and Abbott 1962).

There are several methods for the calculation of fast neutron removal cross section of materials. The conventional method for the quantitative determination of $\left(\Sigma_{R}\right)\left(\mathrm{cm}^{-1}\right)$ for fast neutrons is based on manual calculations and is applied 
for several materials and composites (Glasstone and Sesonske 2012). The values obtained manually for fast neutron removal cross section are in good agreement (within about $10 \%$ ) with values determined experimentally (El-Khayatt 2010). El-Khayatt and Abdo have developed MERCSF-N program for the calculation of fast neutron removal cross sections for materials (El-Khayatt and Abdo 2009). The results of the MERCSF-N program were validated with previously published results and confirmed a good agreement. El-Khayatt has developed an NXcom program for the determination of the removal and attenuation coefficients of transmitted fast neutrons and $\gamma$-rays, respectively (ElKhayatt 2011). Mass attenuation coefficient values calculated using the NXcom program have been confirmed by comparing them with the results of the WinXCom program. The NXcom program is a simple and easy method for the determination of neutron shielding performance. The effective fast neutron removal cross sections $\left(\Sigma_{R}\right)$ can be determined using the NXcom program (Yllmaz et al. 2011; Cataldo et al. 2019). There are some studies reported on the use of polymers as efficient neutron shielding materials (El Abd and Elkady 2014; Elmahroug et al. 2014; Jumpee and Wongsawaeng 2015; Mann et al. 2015a, b; Elwahab et al. 2019; Kaçal et al. 2019; Abdalsalam et al. 2020).

\section{Comparison}

The most widely used materials are polymer materials and polymer composites due to their unique characteristics such as thermal-electrical insulation, corrosion resistance, mechanical and radiation shielding properties. However, many environmental issues concerning the use of such materials is rising pollution rates due to the effects of plastic residues which are gathered in nature and landfills (Hopewell et al. 2009).

Various strategies have been developed towards using and recycling polymer materials and their composites via different processes to maintain eco-friendly and recyclable materials. The main concern of researchers all over the world is to develop and synthesize new materials that would enhance their quality of being eco-friendly and environmentally sustainable. To reduce the negative impact of solid wastes on the environment, researchers were extremely motivated to increase their efforts towards using sustainable and recyclable materials (Liikanen et al. 2019). Based on the characteristics of the produced waste, two types can be categorized: hazardous and nonhazardous waste. Hazardous waste contains materials that have detrimental effects on humans and the environment (Ma et al. 2018).

Great attempts have been dedicated to using recycled polymers and polymer composites in many applications mainly as radiation shielding materials against harmful types of ionizing radiation. A brief comparison is done between the mass attenuation coefficients of some polymers and their reinforced composites which reveal the importance of filler addition in improving the shielding behaviour of polymer-composite materials. Table 2 illustrates the comparison in mass attenuation coefficients of polymer materials and their composites. Also, few polymer-composite materials which revealed significant radiation shielding performance were compared to concrete in terms of mass attenuation coefficient and half-value layer as illustrated in Figs. 11 and 12 , respectively. Figure 11 shows the values of mass attenuation coefficients of some polymer-composite materials compared to concrete at energy $661.66 \mathrm{keV}$. The composites (20\% hematite/polystyrene, $50 \%$ lead oxide/polystyrene, $50 \%$ lead oxide/high-density polyethylene, and $40 \%$ zinc oxide/high-density polyethylene) were chosen based on their high performance of shielding against gamma radiation. The graph confirms that the polymer-composite materials having high amounts of fillers are more likely to attenuate gamma radiation compared to low amounts of fillers. Consequently, the presence of nanoparticles that have a high surface-tovolume ratio as fillers increases the probability of interaction between the photon beam and the composite. Also, the fillers have high electron density and can be uniformly distributed within the polymer matrix, thus enhancing the attenuation mechanism.

Figure 12 reveals the values of another important parameter for selecting the best material in radiation shielding, the half-value layer (HVL). The composites (50\% hematite/ polystyrene, $50 \%$ lead oxide/high-density polyethylene, $20 \%$ zinc oxide/polyacrylamide (PAM), and $40 \%$ zinc oxide/highdensity polyethylene) were chosen based on their lowest values of half-value layer (HVL) since the lowest half-value layer (HVL) values are attributed to better shielding materials. Half-value layer (HVL) is a frequently used parameter that describes the penetration of radiation through objects and also the penetration ability. The fillers used have high densities so that the values of half-value layer decrease by increasing filler loading and are compared to concrete.

Table 3 shows the comparison between polymer materials and other materials such as glasses, flay ash bricks, alloys, and concretes in terms of macroscopic removal cross sections $\left(\Sigma_{R}\right)$. For the comparison, the material with higher values of macroscopic removal cross sections among the studied materials has been chosen. For example, 8 different fly ash bricks with varying compositions have been studied (Singh and Badiger 2013). Among these 8 different studied samples, fly ash brick sample 1 shows the higher values of $\Sigma_{R}$ and that has been taken for comparison. Polymer materials have higher values of $\Sigma_{R}$ than fly ash bricks, bismuth tellurite and bismuth boro-tellurite $\left(\mathrm{TeO}_{2}\right)_{49}\left(\mathrm{~B}_{2} \mathrm{O}_{3}\right)_{21}\left(\mathrm{Bi}_{2} \mathrm{O}_{3}\right)_{30}$ glasses, leaded brass alloys, some ordinary concrete. Thus, it can be concluded that polymer materials are better neutron absorbers. 
Table 2 Comparison between mass attenuation coefficients of polymer materials and their composites

\begin{tabular}{lll}
\hline S. n.o Authors & Material & $\begin{array}{l}\text { Mass attenuation coefficient } \mu_{\mathrm{m}} \\
\left(\mathrm{cm}^{2} \cdot \mathrm{g}^{-1}\right) \\
59.53 \mathrm{keV} 80.99 \mathrm{keV} 356.01 \mathrm{keV}\end{array}$ \\
& & $661.66 \mathrm{keV} 1173.25 \mathrm{keV}$ \\
\hline
\end{tabular}

$1 \quad$ (Atta et al. 2015)

2

(Sharma et al. 2020)

3

(Mahmoud et al. 2018a, b)

4

(Akman et al. 2020)

5

(Buyukyildiz and Kurudirek 2016)

6

(Abbasova et al. 2019)

7

(Li et al. 2017)

8

(Nasehi and Ismail 2019)

9

(Agar et al. 2019)

\section{Control}

Styrene butadiene rubber (SBR-1502)/montmorillonite + titanium(II) oxide

Styrene butadiene rubber (SBR-1502)/montmorillonite + ferric(III) oxide

Styrene butadiene rubber (SBR-1502)/montmorillonite + zinc(II) oxide

Styrene butadiene rubber (SBR-1502)/montmorillonite + molybdenum(II) oxide

Bismuth oxychloride-filled polyester concretes (5\%)

Bismuth oxychloride (10\%)

Bismuth oxychloride (15\%)

Bismuth oxychloride (20\%)

High-density polyethylene

$50 \%$ Nano lead-oxide/high-density polyethylene

$10 \%$ Lead(II) iodide/polyester

$20 \%$ Lead(II) iodide/polyester

Unfilled polyethersulfone

Unfilled polyetherimide

Unfilled acrylonitrile butadiene styrene copolymer

Unfilled polycarbonate

Acrylonitrile butadiene styrene $(45 \%)+150 \mu \mathrm{m}$ copper powder (55\%)

Polypropylene copolymer $(15 \%)+$ iron oxide pow$\operatorname{der}(75 \%)+$ impact modifier (QUEO 8210, 10\%)

Polyphthalamide $(40 \%)+$ chopped carbon fiber $(30 \%)+$ chopped glass fiber $(30 \%)$

Polyphthalamide $(40 \%)+$ chopped glass fiber $(60 \%)$

Unfilled polyphthalamide

Zirconium

Acrylic

Composite (Ba, Al, Si)

Aluminum

Basalt fiber (BF) composite

Basalt fiber/erbium oxide composite

Polyacrylamide/zinc oxide composite 5\%

Polyacrylamide/zinc oxide composite $10 \%$

Polyacrylamide/zinc oxide composite $15 \%$

Polyacrylamide/zinc oxide composite $20 \%$

Bulk zinc oxide

Palladium Pd/silver Ag-based alloys Pd77/Ag23

Palladium Pd 75/silver Ag25

Silver Ag70/palladium Pd30

Palladium Pd 70/Silver Ag30

\begin{tabular}{|c|c|c|c|c|}
\hline- & - & - & 0.0020 & - \\
\hline- & - & - & 0.0258 & - \\
\hline - & - & - & 0.0262 & - \\
\hline- & - & - & 0.0284 & - \\
\hline- & - & - & 0.0304 & - \\
\hline 0.3787 & 0.2539 & 0.1067 & 0.0804 & 0.0604 \\
\hline 0.5710 & 0.3449 & 0.1182 & 0.0798 & 0.0644 \\
\hline 0.6784 & 0.4148 & 0.1261 & 0.0851 & 0.0605 \\
\hline 0.8273 & 0.4819 & 0.1253 & 0.0848 & 0.0638 \\
\hline 0.170 & 0.159 & 0.102 & 0.079 & 0.060 \\
\hline 2.717 & 1.262 & 0.222 & 0.114 & 0.073 \\
\hline 0.716 & 0.412 & 0.111 & 0.082 & 0.061 \\
\hline 1.165 & 0.628 & 0.120 & 0.0849 & 0.058 \\
\hline- & 0.165 & 0.094 & - & - \\
\hline - & 0.152 & 0.095 & - & - \\
\hline- & 0.151 & 0.095 & - & - \\
\hline- & 0.153 & 0.095 & - & - \\
\hline- & 0.163 & 0.096 & - & - \\
\hline- & 0.175 & 0.095 & - & - \\
\hline- & 0.159 & 0.096 & - & - \\
\hline- & 0.162 & 0.096 & - & - \\
\hline & 0.151 & 0.095 & - & - \\
\hline- & - & 0.095 & 0.057 & - \\
\hline - & - & 0.101 & 0.110 & - \\
\hline- & - & 0.117 & 0.084 & - \\
\hline 0.247 & 0.182 & 0.096 & 0.074 & - \\
\hline 0.289 & 0.203 & 0.100 & 0.077 & - \\
\hline 0.734 & 0.407 & 0.104 & 0.078 & - \\
\hline- & - & 0.105 & 0.082 & 0.071 \\
\hline- & - & 0.105 & 0.081 & 0.062 \\
\hline- & - & 0.105 & 0.081 & 0.061 \\
\hline- & - & 0.105 & 0.080 & 0.061 \\
\hline- & - & 0.101 & 0.739 & 0.054 \\
\hline - & 2.334 & 0.119 & 0.072 & 0.051 \\
\hline- & 2.356 & 0.119 & 0.073 & 0.052 \\
\hline- & 2.402 & 0.123 & 0.074 & 0.051 \\
\hline- & 2.388 & 0.124 & 0.072 & 0.051 \\
\hline
\end{tabular}


Table 2 (continued)

\begin{tabular}{|c|c|c|c|c|c|c|c|}
\hline \multirow{2}{*}{$\begin{array}{l}\text { S. n.o } \\
10\end{array}$} & \multirow{2}{*}{$\begin{array}{l}\text { Authors } \\
\text { (Bagheri et al. 2018) }\end{array}$} & \multirow{2}{*}{$\begin{array}{l}\text { Material } \\
\begin{array}{l}\text { Unsaturated polyester (UP) resin } 5 \mathrm{wt} \% \mathrm{UP} / \text { nanoclay } \\
\text { composites, }\end{array}\end{array}$} & \multicolumn{5}{|c|}{$\begin{array}{l}\text { Mass attenuation coefficient } \mu_{\mathrm{m}} \\
\left(\mathrm{cm}^{2} \mathrm{~g}^{-1}\right) \\
59.53 \mathrm{keV} 80.99 \mathrm{keV} 356.01 \mathrm{keV} \\
661.66 \mathrm{keV} 1173.25 \mathrm{keV}\end{array}$} \\
\hline & & & - & - & 0.100 & 0.074 & 0.033 \\
\hline & & UP/nanoclay composites /lead oxide UPCL10, & - & - & 0.120 & 0.078 & 0.032 \\
\hline & & UP/nanoclay composites (UPCL20) & - & - & 0.131 & 0.083 & 0.031 \\
\hline & & UP/nanoclay composites (UPCL30) & - & - & 0.145 & 0.084 & 0.031 \\
\hline & & Per hydro-polysilaxane & - & 0.187 & - & 0.081 & 0.059 \\
\hline & & Poly dimethyl silaxane & - & 0.189 & - & 0.082 & 0.061 \\
\hline & & Methylsilses quioxane & - & 0.179 & - & 0.08 & 0.059 \\
\hline & & Silalkalyene polymer & - & 0.181 & - & 0.081 & 0.061 \\
\hline \multirow[t]{6}{*}{11} & (Belgin and Aycik 2015) & Lead & 0.896 & 0.357 & - & 0.100 & 0.056 \\
\hline & & $\begin{array}{l}\text { Isophthalic polyester (PES) based and natural mineral } \\
\text { (hematite) HPES-10 }\end{array}$ & 0.258 & 0.242 & - & 0.106 & 0.091 \\
\hline & & $\begin{array}{l}\text { Isophthalic polyester (PES) based and natural mineral } \\
\text { (hematite) HPES-20 }\end{array}$ & 0.350 & 0.238 & - & 0.112 & 0.084 \\
\hline & & $\begin{array}{l}\text { Isophthalic polyester (PES) based and natural mineral } \\
\text { (hematite) HPES-30 }\end{array}$ & 0.423 & 0.321 & - & 0.109 & 0.083 \\
\hline & & $\begin{array}{l}\text { Isophthalic polyester (PES) based and natural mineral } \\
\text { (hematite) HPES-40 }\end{array}$ & 0.497 & 0.347 & - & 0.098 & 0.092 \\
\hline & & $\begin{array}{l}\text { Isophthalic polyester (PES) based and natural mineral } \\
\text { (hematite) HPES-50 }\end{array}$ & 0.606 & 0.383 & & 0.098 & 0.083 \\
\hline \multirow[t]{2}{*}{12} & (Abdo et al. 2003) & Fiber-plastic & - & - & - & - & 0.0576 \\
\hline & & Fiber-plastic-lead (FPPb) composite & - & - & - & - & 0.0546 \\
\hline \multirow[t]{3}{*}{13} & (Biswas et al. 2016) & Polyboron & - & - & - & 0.086 & 0.065 \\
\hline & & Pure polyethylene & - & - & - & 0.088 & 0.067 \\
\hline & & Borated polyethylene & - & - & - & 0.082 & 0.062 \\
\hline \multirow[t]{7}{*}{14} & (Harish et al. 2012) & Isophthalic resin (ISO) $+0 \%$ lead oxide & - & - & - & 0.082 & - \\
\hline & & Isophthalic resin (ISO) $+5 \%$ lead oxide & - & - & - & 0.081 & - \\
\hline & & Isophthalic resin (ISO) $+10 \%$ lead oxide & - & - & - & 0.084 & - \\
\hline & & Isophthalic resin (ISO) $+20 \%$ lead oxide & - & - & - & 0.088 & - \\
\hline & & Isophthalic resin (ISO) $+30 \%$ lead oxide & - & - & - & 0.088 & - \\
\hline & & Isophthalic resin (ISO) $+40 \%$ lead oxide & - & - & - & 0.093 & - \\
\hline & & Isophthalic resin (ISO) $+50 \%$ lead oxide & - & - & - & 0.094 & - \\
\hline \multirow[t]{5}{*}{15} & (Mahmoud et al. 2018a, b) & Raw high-density polyethylene ( $0 \%$ lead oxide) & 0.216 & 0.209 & 0.129 & 0.099 & 0.069 \\
\hline & & $\begin{array}{l}\text { Raw high-density polyethylene-lead oxide } 10 \% \text { bulk lead } \\
\text { oxide }\end{array}$ & 0.685 & 0.406 & 0.144 & 0.100 & 0.070 \\
\hline & & $\begin{array}{l}\text { Raw high-density polyethylene-lead oxide } 50 \% \text { bulk lead } \\
\text { oxide }\end{array}$ & 3.158 & 1.468 & 0.257 & 0.133 & 0.083 \\
\hline & & $\begin{array}{l}\text { Raw high-density polyethylene-lead oxide } 10 \% \text { lead } \\
\text { oxide nanoparticles }\end{array}$ & 0.742 & 0.431 & 0.159 & 0.110 & 0.073 \\
\hline & & $\begin{array}{l}\text { Raw high-density polyethylene-lead oxide } 50 \% \text { lead } \\
\text { oxide nanoparticles }\end{array}$ & 3.407 & 1.580 & 0.278 & 0.143 & 0.087 \\
\hline
\end{tabular}


Table 2 (continued)

\begin{tabular}{|c|c|c|c|c|c|c|c|}
\hline \multirow{2}{*}{$\begin{array}{l}\text { S. n.o } \\
16\end{array}$} & \multirow{2}{*}{$\begin{array}{l}\text { Authors } \\
\text { (Alsayed et al. 2020) }\end{array}$} & \multirow{2}{*}{$\begin{array}{l}\text { Material } \\
\text { High-density polyethylene }\end{array}$} & \multicolumn{5}{|c|}{$\begin{array}{l}\text { Mass attenuation coefficient } \mu_{\mathrm{m}} \\
\left(\mathrm{cm}^{2} \cdot \mathrm{g}^{-1}\right) \\
59.53 \mathrm{keV} 80.99 \mathrm{keV} 356.01 \mathrm{keV} \\
661.66 \mathrm{keV} 1173.25 \mathrm{keV}\end{array}$} \\
\hline & & & 0.196 & 0.116 & 0.090 & 0.070 & 0.065 \\
\hline & & 10\% High-density polyethylene /bulk zinc oxide & 0.318 & 0.108 & 0.085 & 0.068 & 0.061 \\
\hline & & 20\% High-density polyethylene /bulk zinc oxide & 0.455 & 0.112 & 0.087 & 0.067 & 0.062 \\
\hline & & $30 \%$ High-density polyethylene /bulk zinc oxide & 0.579 & 0.0107 & 0.083 & 0.065 & 0.061 \\
\hline & & 40\% High-density polyethylene /bulk zinc oxide & 0.703 & 0.111 & 0.083 & 0.065 & 0.061 \\
\hline & & $\begin{array}{l}\text { 10\% High-density polyethylene /bulk zinc oxide nano- } \\
\text { particles }\end{array}$ & 0.397 & 0.111 & 0.090 & 0.072 & 0.067 \\
\hline & & $\begin{array}{l}20 \% \text { High-density polyethylene /bulk zinc oxide nano- } \\
\text { particles }\end{array}$ & 0.483 & 0.126 & 0.097 & 0.077 & 0.069 \\
\hline & & $\begin{array}{l}\text { 30\% High-density polyethylene /bulk zinc oxide nano- } \\
\text { particles }\end{array}$ & 0.636 & 0.123 & 0.099 & 0.078 & 0.073 \\
\hline & & $\begin{array}{l}40 \% \text { High-density polyethylene/bulk zinc oxide nanopar- } \\
\text { ticles }\end{array}$ & 0.077 & 0.124 & 0.099 & 0.077 & 0.070 \\
\hline \multirow[t]{4}{*}{17} & (Sheela et al. 2019) & High-density polyethylene & 0.167 & - & - & - & - \\
\hline & & High-density polyethylene $+10 \%$ Bismuth & 0.609 & - & - & - & - \\
\hline & & High-density polyethylene $+20 \%$ Bismuth & 0.879 & - & - & - & - \\
\hline & & High-density polyethylene $+40 \%$ Bismuth & 2.168 & - & - & - & - \\
\hline
\end{tabular}

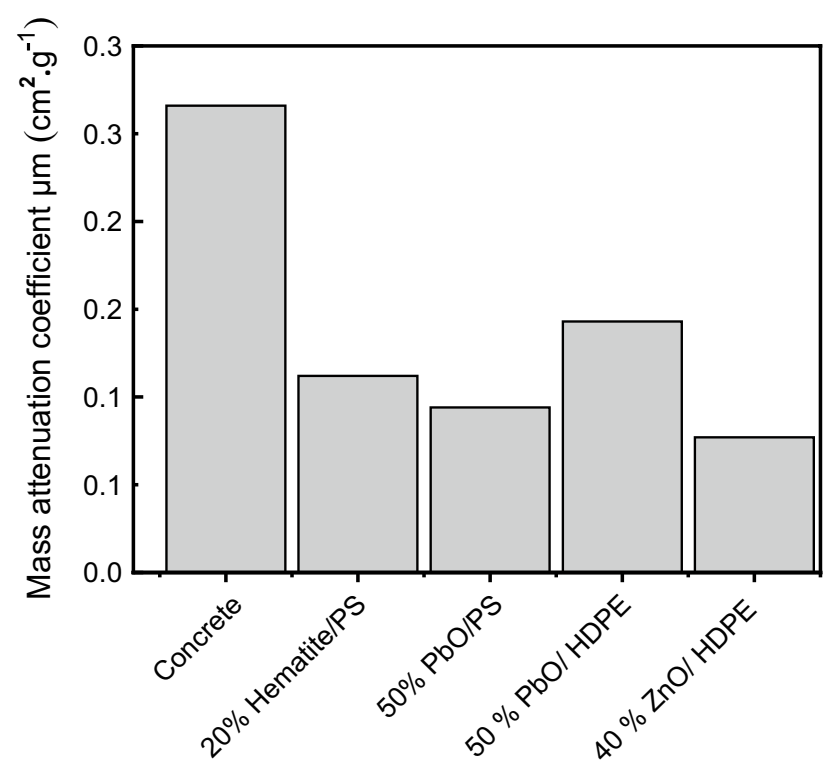

Fig. 11 Mass attenuation coefficient of polymer nanocomposites: $20 \%$ hematite/polystyrene, $50 \%$ lead oxide/polystyrene, $50 \%$ lead oxide/high-density polyethylene, and $40 \%$ zinc oxide/high-density polyethylene compared to concrete

\section{Conclusion}

The continuously growing demand for radiological protective materials has been discussed. The radiation shielding capabilities of a material depend on its material properties along with origin, type, energy, and exposure time of radiation, secondary radiations, and thickness of the material. The important disadvantages which limit its field of application and usage of lead and other conventionally used shielding materials have been covered. Thus, the urgent need for new radiation shielding materials is clear. Suitable to their superior properties, the polymer materials are promising candidates for mixed neutron-gamma-rays shielding. In this regard, numerous researchers have studied polymer and its composites formed by the incorporation of bulk and micromaterials. The radiation shielding abilities of such formed composite materials are increased. Nanostructure materials have recently concerned a lot of attention to scientists because of their potential applications in the development of several new technologies. One of the most applications is the radiation shielding materials which diminishes the hazard humans' dosage by interacting with gamma-ray radiations and decreasing its power. 


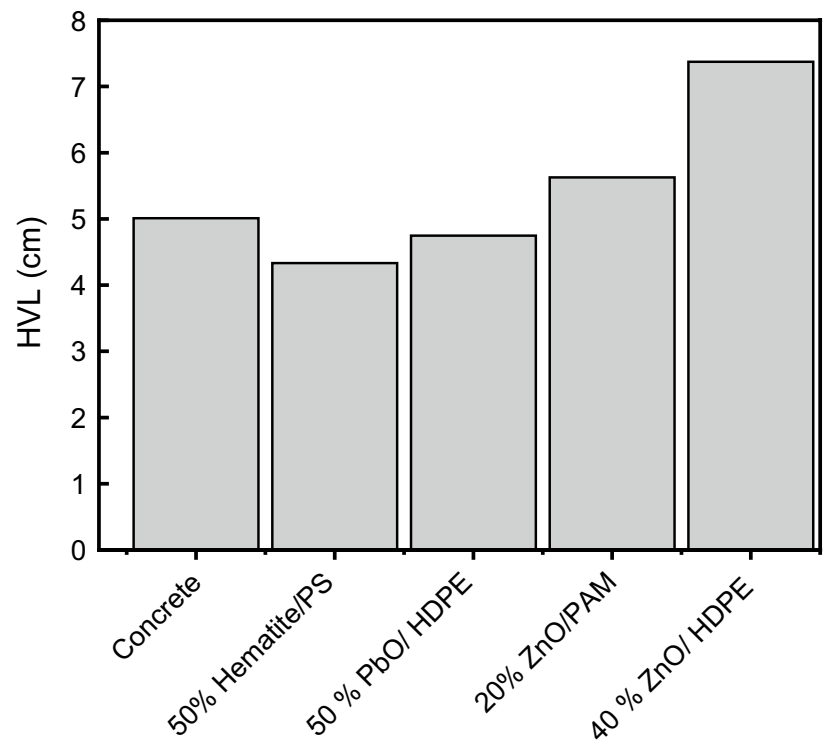

Fig. 12 Half-value layer (HVL) measured in $\mathrm{cm}$ of polymer nanocomposites:50\% hematite/polystyrene, $50 \%$ lead oxide/high-density polyethylene, $20 \%$ zinc oxide /polyacrylamide (PAM), and $40 \%$ zinc oxide/high-density polyethylene compared to concrete. The characteristics of the radiation shield are used to determine their performance against gamma radiation. The incorporation of fillers into the polymer matrices improves the properties of these polymers and compensates for the drawbacks such as mechanical failure and cracks. The filler interacts with the polymer matrix by facilitating the interlocking mechanism of polymeric chains and thus increases the hardness of the composite (Rajendran et al. 2011). Also, the type, concentration, and size of filler are important parameters to be considered when synthesizing a polymer composite. The nanoparticles with their large surface-to-volume ratio are reactive fillers that can be dispersed easily within the matrix and form an interphase region between the surface of the particle and the matrix itself (Puglia and Kenny 2018)

Based on the previously published experimental results, it is clear that the polymer composites formed by the impregnation of nanomolecules are a better shield for gamma rays than the polymer itself, and the usefulness of polymer materials for neutron shielding is clear enough. Moreover, it is expected to use waste plastic materials by recycling in new areas by obtaining novel and sustainable composites with low thickness and developed shielding properties to increase the economic feasibility and reduce the harmfulness. Recycling is the best way to manage plastic wastes since it reduces environmental impact, resource depletion, and pollution. Besides, recycling plastics consumes a smaller amount of energy when compared to energy consumption in new virgin resin production. Fundamentally, high levels of recycling, as with a reduction in use, reuse, and repair or remanufacturing, can allow for a given level of product service with lower material input than would otherwise be required. Therefore, recycling can decrease energy and material used per unit of production and so yield improved eco-efficiency.

Several points can be summarized from the recent review article such as low atomic number polymeric materials alone which are not sufficient to attenuate/absorb highly energetic ionizing radiations such as gamma rays. One of the emerging solutions is the incorporation of other materials like high atomic number elements (other than lead), metal oxides, metal oxides, graphitic nanofibers, etc. These polymer composites have an effective low weight in comparison with a lead yet are capable shields against gamma radiation. By way of the evolution of nanotechnology, the ongoing trend is to develop novel polymer nanocomposites that would be lightweight, multifunctional, and efficient gamma-radiation shields. The world is desirous of more environmentally forthcoming materials and this has made investigators turn their attention to biodegradable or recyclable polymer nanocomposites and they have been effectively used as reinforcements in radiological protection replacing conventional materials. In this paper, a detailed review of the synthesis roots of polymer composites and their gamma-ray and neutron radiation attenuation properties has been given. This may supply an insight into polymer composites and would be useful to new researchers working in nuclear medicine, radiation therapy, nuclear industry, radiological protection, etc. The polymer matrices with some neutron absorbers impregnated by materials of the different atomic numbers are much better shielding candidates against nuclear
Table 3 Comparison of $\Sigma_{R}$ for polymers with literature

\begin{tabular}{llll}
\hline S. no. & Authors & Material & $\Sigma_{R}\left(\mathrm{~cm}^{-1}\right)$ \\
\hline 1 & (Singh and Badiger 2013) & Fly Ash Brick 1 & 0.0663 \\
2 & (Y1lmaz et al. 2011) & Mortar mixture (MO) concrete & 0.0869 \\
3 & (Lakshminarayana et al. 2020) & Bismuth tellurite and bismuth boro-tellurite & 0.1080 \\
& & $\left(\mathrm{TeO}_{2}\right)_{49}\left(\mathrm{~B}_{2} \mathrm{O}_{3}\right)_{21}\left(\mathrm{Bi}_{2} \mathrm{O}_{3}\right)_{30}$ glass & \\
4 & $($ Şakar et al. 2019) & Leaded brass, $\mathrm{Cu}_{76} \mathrm{Zn}_{21} \mathrm{P}$ & 0.1130 \\
5 & $($ Kaçal et al. 2019) & Polyamide-6 & 0.1151 \\
6 & (Sayyed 2016) & Polyethylenimine (PEI) & 0.1182 \\
7 & (Elwahab et al. 2019) & High-density polyethylene + Borax (7.72\%) & 0.1570 \\
8 & (Elmahroug et al. 2014) & K-Resin & 0.1870 \\
9 & (El Abd and Elkady 2014) & Polyethylene (PE) & 0.1870 \\
\hline
\end{tabular}


reactors, radioactive sources, collimators, etc., and these polymer composites are environmentally sound and nontoxic. Moreover, in the upcoming characterization studies such as X-ray diffraction (XRD), scanning electron microscope (SEM), energy-dispersive spectroscopy (EDAX), and Fourier transform infrared spectroscopy (FTIR) of polymer composites could be discussed later on in detail. However, further deep studies are required to get insight into radiation attenuation/absorption properties of the nanomaterials against different types of radiation.

This study has presented a reasonable review of some polymer-composite materials and their properties by introducing the importance of reusing and recycling some polymers after treatment in various applications mainly in radiation shielding against gamma rays. The addition of a certain type of fillers (metals, metal oxides, ceramics, etc.) is extremely important in enhancing the hardness, strength, and radiation absorption abilities of the synthesized composite. The future of polymer composite materials is promising, due to the extensive use of these novel materials in many fields. Emphasis on the use of recyclable and reusable polymers should be focused to reduce the harmful effects and toxicity of thermoplastics which are not degradable. Moreover, there is a need to figure out best practices to improve the properties of recyclable and reprocessed polymers to allow their use in the nuclear industry, medical diagnostics, nuclear reactors, and nuclear research organizations.

Acknowledgements One of the authors, Miss. Chaitali V. More, would like to thank Chhatrapati Shahu Maharaj Research Training and Human Development Institute (SARTHI), Pune (Govt. of Maharashtra, India), for the financial support under the scheme CSMNRF-2019.

Author contributions CVM contributed to idea for the article, literature search and data analysis, writing — original draft, writing — review and editing. ZA contributed to literature search and data analysis, writing - original draft, writing - review and editing. MSB contributed to writing - review and editing, supervision. AAT contributed to supervision. PPP contributed to supervision.

\section{Compliance with ethical standards}

Conflict of interest The authors declare that they have no known competing financial interests or personal relationships that could have appeared to influence the work reported in this paper.

Ethical approval We confirm that this work is original and has not been published elsewhere, nor it is currently under consideration for publication elsewhere.

\section{References}

Abbasova N, Yüksel Z, Abbasov E, Gülbiçim H, Tufan MÇ (2019) Investigation of gamma-ray attenuation parameters of some materials used in dental applications. Results Phys 12:2202-2205
Abdalsalam A, Taki M, Abu Mhareb M, Alım B, Ali B, Şakar E (2020) $\mathrm{MoO}_{3}$ reinforced ultra high molecular weight PE for neutrons shielding applications. Radiat Phys Chem 172:108852. https:// doi.org/10.1016/j.radphyschem.2020.108852

Abdel-Gawwad H, Mohammed M, Zakey S (2020) Preparation, performance, and stability of alkali-activated concrete waste-leadbearing sludge composites. J Clean Prod 259:120924. https://doi. org/10.1016/j.jclepro.2020.120924

Abdel-Haseiba A, Ahmeda Z, Hassanb MM (2018) Investigation of the gamma rays attenuation coefficients by experimental and MCNP simulation for polyamide 6/acrylonitrile-butadiene-styrene blends. J Nucl Radiat Phys 13(1):81-89

Abdo AE-S, Ali M, Ismail M (2003) Natural fibre high-density polyethylene and lead oxide composites for radiation shielding. Radiat Phys Chem 66(3):185-195

Adeosun SO, Lawal G, Balogun SA, Akpan EI (2012) Review of green polymer nanocomposites. Int J Innov Res Sci Eng Technol 11(04):385

Adhikary KB, Pang S, Staiger MP (2008) Dimensional stability and mechanical behaviour of wood-plastic composites based on recycled and virgin high-density polyethylene (HDPE). Compos B Eng 39(5):807-815

Afshar M, Morshedian J, Ahmadi S (2019) Radiation attenuation capability and flow characteristics of HDPE composite loaded with W, $\mathrm{MoS}_{2}$, and B4C. Polym Compos 40(1):149-158. https://doi. org/10.1002/pc. 24620

Agar O, Sayyed MI, Akman F, Tekin HO, Kaçal MR (2019) An extensive investigation on gamma ray shielding features of $\mathrm{Pd} /$ Ag-based alloys. Nucl Eng Technol 51(3):853-859. https://doi. org/10.1016/j.net.2018.12.014

Aghaz A, Faghihi R, Mortazavi SMJ, Haghparast A, Mehdizadeh S, Sina S (2016) Radiation attenuation properties of shields containing micro and $\mathrm{Nano}_{\mathrm{WO}_{3}}$ in diagnostic $\mathrm{X}$-ray energy range. Int J Radiat-Res 14(2):127-131. https://doi.org/10.18869/acadp ub.ijrr.14.2.127

Agool IR, Kadhim KJ, Hashim A (2017) Synthesis of (PVA-PEG$\mathrm{PVP}-\mathrm{ZrO}_{2}$ ) nanocomposites for energy release and gamma shielding applications. Int J Plast Technol 21(2):444-453. https ://doi.org/10.1007/s12588-017-9196-1

Akkurt I, El-Khayatt AM (2013) Effective atomic number and electron density of marble concrete. J Radioanal Nucl Chem. https://doi. org/10.1007/s10967-012-2111-5

Akkurt I, Kılıncarslan S, Basyigit C, Mavi B, Akyıldırım H (2009) Investigation of photon attenuation coefficient for pumice. Int J Phys Sci 4(10):588-591

Akman F, Kaçal MR, Almousa N, Sayyed MI, Polat H (2020) Gammaray attenuation parameters for polymer composites reinforced with $\mathrm{BaTiO}_{3}$ and $\mathrm{CaWO}_{4}$ compounds. Prog Nucl Energy 121:103257. https://doi.org/10.1016/j.pnucene.2020.103257

Akman F, Ogul H, Kaçal MR, Polat H, Dilsiz K, Agar O (2021) Gamma attenuation characteristics of CdTe-doped polyester composites. Prog Nucl Energy 131:103608. https://doi.org/10.1016/j.pnuce ne. 2020.103608

Alavian H, Tavakoli-Anbaran H (2019) Study on gamma shielding polymer composites reinforced with different sizes and proportions of tungsten particles using MCNP code. Prog Nucl Energy 115:91-98

Alavian H, Tavakoli-Anbaran H (2020) Comparative study of mass attenuation coefficients for LDPE/metal oxide composites by Monte Carlo simulations. Eur Phys J Plus 135(1):82

Alavian H, Samie A, Tavakoli-Anbaran H (2020) Experimental and Monte Carlo investigations of gamma ray transmission and buildup factors for inorganic nanoparticle/epoxy composites. Radiat Phys Chem 174:108960

Al-Buriahi MS, Singh VP, Arslan H, Awasarmol VV, Tonguc BT (2020) Gamma-ray attenuation properties of some NLO 
materials: potential use in dosimetry. Radiat Environ Biophys 59(1):145-150. https://doi.org/10.1007/s00411-019-00824-y

Al-Dhuhaibat M, Salman M, Jubier N, Salim A (2020) Improved gamma radiation shielding traits of epoxy composites: Evaluation of mass attenuation coefficient, effective atomic and electron number. Radiat Phys Chem 179:109183. https://doi. org/10.1016/j.radphyschem.2020.109183

Alexandre M, Dubois P (2000) Polymer-layered silicate nanocomposites: preparation, properties and uses of a new class of materials. Mater Sci Eng R Rep 28(1-2):1-63

Al-Sarray E, Günoğlu K, Evcin A, Bezir N (2017) Radiation shielding properties of some composite panel. Acta Phys Pol 132:490-492. https://doi.org/10.12693/APhysPolA.132.490

Alsayed Z, Badawi M, Awad R, Thabet A, El-Khatib A (2019) Study of some $\gamma$-ray attenuation parameters for new shielding materials composed of nano $\mathrm{ZnO}$ blended with high density polyethylene. Nucl Technol Radiat Prot 34:33-33. https://doi.org/10.2298/ NTRP190718033A

Alsayed Z, Badawi M, Awad R, Elkhatib A, Thabet A (2020) Investigation of $\gamma$-ray attenuation coefficients, effective atomic number and electron density for $\mathrm{ZnO} / \mathrm{HDPE}$ composite. Phys Scr. https ://doi.org/10.1088/1402-4896/ab9a6e

Ambika MR, Nagaiah N, Suman SK (2017) Role of bismuth oxide as a reinforcer on gamma shielding ability of unsaturated polyester based polymer composites. J Appl Polym Sci. https://doi. org/10.1002/app.44657

Ameen S, Akhtar MS, Shin HS (2012) Hydrazine chemical sensing by modified electrode based on in situ electrochemically synthesized polyaniline/graphene composite thin film. Sens Actuators B Chem 173:177-183

ANSI/ANS (1991) Gamma-ray attenuation coefficients and buildup factor for engineering materials ANSI/ANS 6.4.3 American Nuclear Society, La Grange Park, Illinois

Ashori A, Sheshmani S (2010) Hybrid composites made from recycled materials: moisture absorption and thickness swelling behavior. Bioresour Technol 101:4717-4720. https://doi.org/10.1016/j. biortech.2010.01.060

Atashi P, Rahmani S, Ahadi B, Rahmati A (2018) Efficient, flexible and lead-free composite based on room temperature vulcanizing silicone rubber $/ \mathrm{W} / \mathrm{Bi}_{2} \mathrm{O}_{3}$ for gamma ray shielding application. J Mater Sci Mater Electron 29:10. https://doi.org/10.1007/s1085 4-018-9344-1

Atta E, Zakaria KM, Madbouly A (2015) Research article study on polymer clay layered nanocomposites as shielding materials for ionizing radiation. Int J Recent Sci Res 6(5):4263-4269

Avella M, Errico M, Martelli S, Martuscelli E (2001) Preparation methodologies of polymer matrix nanocomposites. Appl Organomet Chem 5:435-439

Awadallah-F A, Antar EM (2014) Synthesis of complexed grafted low density polyethylene films and its applicability in nuclear medicine as radiation shielding against technetium-99 m. Polym Plast Technol Eng 53(2):173-180. https://doi.org/10.1080/03602 559.2013.843705

Awaja F, Pavel D (2005) Recycling of PET. Eur Polym J 41:14531477. https://doi.org/10.1016/j.eurpolymj.2005.02.005

Azadbakht B, Bagheri R (2019) Photon interaction properties of different bones from human body using MCNPX, WinXCom, XMuDat, and auto-Zeff programs. J Test Eval 48(6):4608-4622. https ://doi.org/10.1520/JTE20180730

Azman NN, Siddiqui S, Hart R, Low I-M (2013) Effect of particle size, filler loadings and X-ray tube voltage on the transmitted X-ray transmission in tungsten oxide-epoxy composites. Appl Radiat Isot 71(1):62-67

Bagheri K, Razavi SM, Ahmadi SJ, Kosari M, Abolghasemi H (2018) Thermal resistance, tensile properties, and gamma radiation shielding performance of unsaturated polyester/nanoclay/ PbO composites. Radiat Phys Chem 146:5-10. https://doi. org/10.1016/j.radphyschem.2017.12.024

Basfar A, Ali Z (2011) Physicochemical properties of low density polyethylene and ethylene vinyl acetate composites cross-linked by ionizing radiation. Radiat Phys Chem 80:257-263. https://doi. org/10.1016/j.radphyschem.2010.07.043

Bedar A, Lenka RK, Goswami N, Kumar V, Debnath AK, Sen D, Kumar S, Ghodke S, Tewari PK, Bindal RC, Kar S (2019) Polysulfone-ceria mixed-matrix membrane with enhanced radiation resistance behavior. ACS Appl Polym Mater 1(7):1854-1865. https://doi.org/10.1021/acsapm.9b00389

Bel T, Arslan C, Baydogan N (2018) Radiation shielding properties of poly(methyl methacrylate)/colemanite composite for the use in mixed irradiation fields of neutrons and gamma rays. Mater Chem Phys. https://doi.org/10.1016/j.matchemphys.2018.09.014

Belgin EE, Aycik GA (2015) Preparation and radiation attenuation performances of metal oxide filled polyethylene based composites for ionizing electromagnetic radiation shielding applications. J Radiational Nucl Chem 306(1):107-117

Berger MJ, Hubbell JH (1987) NIST standard reference database 8 (XGAM). NBSIR 87-3597, XCOM: Photon Cross Sections Database. 20899

Berger MJ, Spencer LVC (1959) Penetration of gamma rays from isotropic sources through aluminum and concrete, US Department of Commerce, Office of Technical Services

Bhattacharya M (2016) Polymer nanocomposites-a comparison between carbon nanotubes, graphene, and clay as nanofillers. Materials 9:262. https://doi.org/10.3390/ma9040262

Bhosale RR, More CV, Gaikwad DK, Pawar PP, Rode MN (2017) Radiation shielding and gamma ray attenuation properties of some polymers. Nucl Technol Radiat Prot 32(3):288-293

Biswas R, Sahadath H, Mollah AS, Huq MF (2016) Calculation of gamma-ray attenuation parameters for locally developed shielding material: polyboron. J Radiat Res Appl Sci 9(1):26-34. https ://doi.org/10.1016/j.jrras.2015.08.005

Blizard E, Abbott L (1962) Reactor handbook: part b: shielding, vol III. Wiley, New York

Buyukyildiz M, Kurudirek M (2016) A study of the effective atomic number of $\mathrm{SixPb} 0.7-\mathrm{x}\left(\mathrm{Fe}_{2} \mathrm{O}_{3}\right) 0.3$ ternary alloys for photons. Nucl Technol Radiat Prot 31(4):327-334

Callister WD (2007) Materials science and engineering: an introduction. Wiley, New York

Camargo PHC, Satyanarayana KG, Wypych F (2009) Nanocomposites: synthesis, structure, properties and new application opportunities. Mater Res 12(1):1-39

Cao D, Yang G, Bourham M, Moneghan D (2020) Gamma radiation shielding properties of poly(methyl methacrylate) $/ \mathrm{Bi}_{2} \mathrm{O}_{3}$ composites. Nucl Eng Technol 52(11):2613-2619. https://doi. org/10.1016/j.net.2020.04.026

Cassagnau P, Bounor-Legaré V, Fenouillot F (2007) Reactive processing of thermoplastic polymers: a review of the fundamental aspects. Int Polym Process 22(3):218-258. https://doi. org/10.3139/217.2032

Cataldo F, Prata MJF (2019) Neutron radiation shielding with PUR composites loaded with B4C or graphite. Fuller Nanotub Carbon Nanostruct 27(7):531-537

Ceh J, Youd T, Mastrovich Z, Peterson C, Khan S, Sasser TA, Sander IM, Doney J, Turner C, Leevy WM (2017) Bismuth infusion of ABS enables additive manufacturing of complex radiological phantoms and shielding equipment. Sensors 17(3):459

Chai H, Tang X, Ni M, Chen F, Zhang Y, Chen D, Qiu Y (2016) Preparation and properties of novel, flexible, lead-free X-rayshielding materials containing tungsten and bismuth(III) oxide. J Appl Polym Sci. https://doi.org/10.1002/app.43012 
Chandler H (1999) Hardness testing. ASM International, Cleveland Chang L, Zhang Y, Liu Y, Fang J, Luan W, Yang X, Zhang W (2015) Preparation and characterization of tungsten/epoxy composites for $\gamma$-rays radiation shielding. Nucl Instrum Methods Phys Res B 356-357:88-93. https://doi.org/10.1016/j.nimb.2015.04.062

Chatterjee S, Krupadam R (2018) Amino acid-imprinted polymers as highly selective $\mathrm{CO}_{2}$ capture materials. Environ Chem Lett. https://doi.org/10.1007/s10311-018-0774-z

Chen L, Wang C, Li Q, Yang S, Hou L, Chen S (2009) In situ synthesis of transparent fluorescent $\mathrm{ZnS}$-polymer nanocomposite hybrids through catalytic chain transfer polymerization technique. J Mater Sci Mater Electron 44(13):3413-3419

Chiang T-C, Liu H, Tsai L, Jiang T, Ma N, Tsai F-C (2020) Improvement of the mechanical property and thermal stability of polypropylene/recycled rubber composite by chemical modification and physical blending. Sci Rep. https://doi.org/10.1038/s4159 8-020-59191-0

Chinchillas-Chinchillas MJ, Gaxiola Hernández A, Alvarado C, Orozco-Carmona V, Cervantes MJ, Rodríguez-Rodríguez M, Castro-Beltrán A (2019) A new application of recycled-PET/ PAN composite nanofibers to cement-based materials. J Clean Prod 252:119827. https://doi.org/10.1016/j.jclepro.2019.11982 7

Cholake S, Rajarao R, Henderson P, Rajagopal R, Sahajwalla V (2017) Composite panels obtained from automotive waste plastics and agricultural macadamia shell waste. J Clean Prod. https://doi. org/10.1016/j.jclepro.2017.03.074

Choppin G, Liljenzin J-O, Rydberg J (2002) Chapter 18. Radiation biology and radiation protection, pp 474-513

Chowreddy RR, Nord-Varhaug K, Rapp F (2019) Recycled poly(ethylene terephthalate)/clay nanocomposites: rheology, thermal and mechanical properties. J Polym Environ 27(1):37-49

Daima H, Shankar S, Anderson A, Selvakannan PR, Bhargava S, Bansal V (2018) Complexation of plasmid DNA and poly(ethylene oxide)/poly(propylene oxide) polymers for safe gene delivery. Environ Chem Lett. https://doi.org/10.1007/s10311-018-0756-1

Das NC, Liu Y, Yang K, Peng W, Maiti S, Wang H (2009) Singlewalled carbon nanotube/poly (methyl methacrylate) composites for electromagnetic interference shielding. Polym Eng Sci 49(8):1627-1634

Dehghani A, Ardekani SM, Al-Maadeed MA, Hassan A, Wahit MU (2013) Mechanical and thermal properties of date palm leaf fiber reinforced recycled poly(ethylene terephthalate) composites. Mater Des 52:841-848

Demir İ, Gümüş M, Gökçe HS (2020) Gamma ray and neutron shielding characteristics of polypropylene fiber-reinforced heavyweight concrete exposed to high temperatures. Constr Build Mater 257:119596. https://doi.org/10.1016/j.conbuildmat.2020.119596

El Abd AA, Elkady AS (2014) A method for simultaneous determination of effective removal cross-section for fast neutrons and mass absorption coefficient for gamma rays. Mater Sci Eng 2(2):1-6

El-Fiki S, El Kameesy SU, Nashar DE, Abou-Leila MA, El-Mansy MK, Ahmed M (2015) Influence of bismuth contents on mechanical and gamma ray attenuation properties of silicone rubber composite. Int J Adv Res 3(6):1035-1041

El-Khatib AM, Abbas MI, Elzaher MA, Badawi MS, Alabsy MT, Alharshan GA, Aloraini DA (2019) Gamma attenuation coefficients of nano cadmium oxide/high density polyethylene composites. Sci Rep 9(1):16012. https://doi.org/10.1038/s4159 8-019-52220-7

El-Khayatt A (2010) Calculation of fast neutron removal cross-sections for some compounds and materials. Ann Nucl Energy 37:218222. https://doi.org/10.1016/j.anucene.2009.10.022

El-Khayatt AM (2011) NXcom - a program for calculating attenuation coefficients of fast neutrons and gamma-rays. Ann Nucl Energy 38(1):128-132
El-Khayatt AM, Abdo AE-S (2009) MERCSF-N: a program for the calculation of fast neutron removal cross sections in composite shields. Ann Nucl Energy 36(6):832-836

Elmahroug Y, Tellili B, Souga C (2014) Determination of shielding parameters for different types of resins. Ann Nucl Energy 63:619-623. https://doi.org/10.1016/j.anucene.2013.09.007

El-Mekkawi D, Abdelwahab NA, Mohamed W, Taha N, AbdelMottaleb M (2019) Solar photocatalytic treatment of industrial wastewater utilizing recycled polymeric disposals as $\mathrm{TiO}_{2}$ supports. J Clean Prod 249:119430. https://doi.org/10.1016/j.jclep ro.2019.119430

Elwahab N, Helal N, Mohamed T, Shahin F, Ali F (2019) New shielding composite paste for mixed fields of fast neutrons and gamma rays. Mater Chem Phys. https://doi.org/10.1016/j.matchemphy s.2019.05.059

Evcın O, Evcin A, Bezir N, Günoğlu K, Ersoy B (2017) Production of barite and boroncarbide doped radiation shielding polymer composite panels. Acta Phys Pol 132:1145-1148. https://doi. org/10.12693/APhysPolA.132.1145

Fontainha CCP, Baptista Neto AT, Santos AP, Faria LOD (2016) P (VDF-TrFE)/ZrO $\mathrm{Zr}_{2}$ polymer-composites for $\mathrm{x}$-ray shielding. Mater Res 19(2):426-433

Gaikwad K, Singh S, Ajji A (2018) Moisture absorbers for food packaging applications. Environ Chem Lett. https://doi.org/10.1007/ s10311-018-0810-z

Galante A, Campos L (2010) Characterization of polycarbonate dosimeter for gamma-radiation dosimetry. In: Proceedings of third European IPRA congress, Helsinki, Finland

Gerward L, Guilbert N, Jensen KB, Levring H (2004) WinXCom-a program for calculating X-ray attenuation coefficients. Radiat Phys Chem 71(3):653-654. https://doi.org/10.1016/j.radphysche m.2004.04.040

Glasstone S, Sesonske A (2012) Nuclear reactor engineering: reactor systems engineering. Springer, New York

Grégorio C, Torri G, Lichtfouse E, Kyzas G, Wilson L, Crini N (2019) Dye removal by biosorption using cross-linked chitosan-based hydrogels. Environ Chem Lett. https://doi.org/10.1007/s1031 1-019-00903-y

Grigoriadou I, Paraskevopoulos K, Chrissafis K, Pavlidou E, Stamkopoulos T-G, Bikiaris D (2011) Effect of different nanoparticles on HDPE UV stability. Polym Degrad Stab 96:151-163. https:// doi.org/10.1016/j.polymdegradstab.2010.10.001

Gryczak M, Wong J, Thiemann C, Ferrari B, Werner I, Petzhold C (2020) Recycled low-density polyethylene composite to mitigate the environmental impacts generated from coal mining waste in Brazil. J Environ Manag 260:110149. https://doi.org/10.1016/j. jenvman.2020.110149

Gu S, Kang X, Wang L, Lichtfouse E, Wang C (2018) Clay mineral adsorbents for heavy metal removal from wastewater: a review. Environ Chem Lett. https://doi.org/10.1007/s10311-018-0813-9

Gudadhe A, Bachhar N, Kumar A, Andrade P, Kumaraswamy G (2019) Three-dimensional printing with waste high-density polyethylene. ACS Appl Polym Mater 1(11):3157-3164. https://doi. org/10.1021/acsapm.9b00813

Gupta AK, Biswal M, Mohanty S, Nayak S (2014) Mechanical and thermal degradation behavior of sisal fiber (SF) reinforced recycled polypropylene (RPP) composites. Fibers Polym 15(5):994-1003

Gurler O, Akar Tarim U (2016) Determination of radiation shielding properties of some polymer and plastic materials against gammarays. Acta Phys Pol 130:236-238. https://doi.org/10.12693/ APhysPolA.130.236

Gwaily SE (2002) Galena/(NR+SBR) rubber composites as gamma radiation shields. Polym Test 21(8):883-887

Hager IZ, Rammah YS, Othman HA, Ibrahim EM, Hassan SF, Sallam FH (2019) Nano-structured natural bentonite clay coated 
by polyvinyl alcohol polymer for gamma rays attenuation. $\mathrm{J}$ Theor Appl Phys 13(2):141-153. https://doi.org/10.1007/s4009 4-019-0332-5

Hamim F, Ghani S, Zainuddin F (2016) Properties of recycled high density polyethylene (RHDPE)/ethylene vinyl acetate (EVA) blends: the effect of blends composition and compatibilisers. J Phys Sci 27:23-39. https://doi.org/10.21315/jps2016.27.2.3

Harima Y (1983) An approximation of gamma-ray buildup factors by modified geometrical progression. Nucl Sci Eng (US) 83:2. https ://doi.org/10.13182/NSE83-A18222

Harish V, Nagaiah N, Kumar HG (2012) Lead oxides filled isophthalic resin polymer composites for gamma radiation shielding applications. Indian J Pure Appl Phys 50:847-850

Harrison C, Burgett E, Hertel N, Grulke E (2008) Polyethylene/boron composites for radiation shielding applications. AIP Conf Proc 969(1):484-491. https://doi.org/10.1063/1.2845006

Hassan H, Badran H, Aydarous A, Sharshar T (2015) Studying the effect of nano lead compounds additives on the concrete shielding properties for $\gamma$-rays. Nucl Instrum Methods Phys Res B 360:81-89

Hebbar R, Isloor A, Inamuddin I, Asiri AM (2017) Carbon nanotube- and graphene-based advanced membrane materials for desalination. Environ Chem Lett. https://doi.org/10.1007/s1031 1-017-0653-z

Hellström K, Dioszegi A, Diaconu L (2017) A broad literature review of density measurements of liquid cast iron. Metals. https://doi. org/10.3390/met7050165

Hopewell J, Dvorak R, Kosior E (2009) Plastics recycling: challenges and opportunities. Philos Trans R Soc Lond B Biol Sci 364:2115-2126. https://doi.org/10.1098/rstb.2008.0311

Hussain R, Haq ZU, Mohammad D (1997) A study of the shielding properties of poly ethylene glycol-lead oxide composite. J Islamic Acad Sci 10(3):81-84

Inacio AL, Nonato RC, Bonse BC (2017) Recycled PP/EPDM/talc reinforced with bamboo fiber: assessment of fiber and compatibilizer content on properties using factorial design. Polym Test 61:214-222

Issa SAM, Mostafa AMA, Hanafy TA, Dong M, Xue X (2019) Comparison study of photon attenuation characteristics of Poly vinyl alcohol (PVA) doped with $\mathrm{Pb}\left(\mathrm{NO}_{3}\right)_{2}$ by MCNP5 code, XCOM and experimental results. Prog Nucl Energy 111:15-23. https:// doi.org/10.1016/j.pnucene.2018.10.018

Jumpee C, Wongsawaeng D (2015) Innovative neutron shielding materials composed of natural rubber-styrene butadiene rubber blends, boron oxide and iron (III) oxide. J Phys Conf Ser 611:012019

Kaçal M, Akman F, Sayyed M (2019) Evaluation of gamma-ray and neutron attenuation properties of some polymers. Nucl Eng Technol 51(3):818-824

Kaçal MR, Polat H, Oltulu M, Akman F, Agar O, Tekin HO (2020) Gamma shielding and compressive strength analyses of polyester composites reinforced with zinc: an experiment, theoretical, and simulation based study. Appl Phys A 126(3):205. https://doi. org/10.1007/s00339-020-3382-2

Kaçal MR, Dilsiz K, Akman F, Polat H (2021) Analysis of radiation attenuation properties for Polyester $/ \mathrm{Li}_{2} \mathrm{WO}_{4}$ composites. Radiat Phys Chem 179:109257. https://doi.org/10.1016/j.radphysche m.2020.109257

Kaloshkin S, Tcherdyntsev V, Gorshenkov M, Gulbin V, Kuznetsov S (2012) Radiation-protective polymer-matrix nanostructured composites. J Alloys Compd 536:S522-S526

Kaphle A, Umapathi NPNA, Daima H (2017) Nanomaterials for agriculture, food and environment: applications, toxicitysss and regulation. Environ Chem Lett. https://doi.org/10.1007/s1031 1-017-0662-y
Kaushik A, Singh M, Verma G (2010) Green nanocomposites based on thermoplastic starch and steam exploded cellulose nanofibrils from wheat straw. Carbohydr Polym 82:337-345. https:// doi.org/10.1016/j.carbpol.2010.04.063

Kazemi F, Malekie S, Hosseini MA (2019) A Monte Carlo study on the shielding properties of a novel polyvinyl alcohol (PVA)/ $\mathrm{WO}_{3}$ composite, against gamma rays, using the MCNPX code. $\mathrm{J}$ Biomed Phys Eng 9(4):465-472. https://doi.org/10.31661/jbpe. v0i0.1114

Kilicoglu O, Kara U, Inanc I (2021) The impact of polymer additive for N95 masks on gamma-ray attenuation properties. Mater Chem Phys 260:124093. https://doi.org/10.1016/j.matchemphy s.2020.124093

Kráčalík M, Pospíšil L, Šlouf M, Mikešová J, Sikora A, Šimoník J, Fortelný I (2008) Effect of glass fibers on rheology, thermal and mechanical properties of recycled PET. Polym Compos 29(8):915-921

Kumar A (2017) Gamma ray shielding properties of $\mathrm{PbO}-\mathrm{Li}_{2} \mathrm{O}-\mathrm{B}_{2} \mathrm{O}_{3}$ glasses. Radiat Phys Chem 136:50-53. https://doi.org/10.1016/j. radphyschem.2017.03.023

Kumar AP, Depan D, Singh Tomer N, Singh RP (2009) Nanoscale particles for polymer degradation and stabilization - trends and future perspectives. Prog Polym Sci 34(6):479-515. https://doi. org/10.1016/j.progpolymsci.2009.01.002

Kumar S, Raju S, Mohana N, Sampath PS, Jayakumari LS (2014) effects of nanomaterials on polymer composites-an expatiate view. Rev Adv Mater Sci 38(1):40-54

Lakshminarayana G, Kebaili I, Dong M, Al-Buriahi M, Dahshan A, Kityk I, Lee D-E, Yoon J, Park T (2020) Estimation of gammarays, and fast and the thermal neutrons attenuation characteristics for bismuth tellurite and bismuth boro-tellurite glass systems. J Mater Sci Mater Electron 55(14):5750-5771

Lee K-H, Noh N-S, Shin D-H, Seo Y (2002) Comparison of plastic types for catalytic degradation of waste plastics into liquid product with spent FCC catalyst. Polym Degrad Stab 78:539-544. https://doi.org/10.1016/S0141-3910(02)00227-6

Lee S, Kang I-A, Doh G-H, Yoon H, Park B-D, Wu Q (2008) Thermal and mechanical properties of wood flour/talc-filled polylactic acid composites: effect of filler content and coupling treatment. J Thermoplast Compos Mater 21:209-223. https://doi. org/10.1177/0892705708089473

Levet A, Kavaz E, Özdemir Y (2020) An experimental study on the investigation of nuclear radiation shielding characteristics in iron-boron alloys. J Alloys Compd 819:152946. https://doi. org/10.1016/j.jallcom.2019.152946

Li R, Gu Y, Wang Y, Yang Z, Li M, Zhang Z (2017) Effect of particle size on gamma radiation shielding property of gadolinium oxide dispersed epoxy resin matrix composite. Mater Res Express 4(3):035035

Li Q, Wei Q, Zheng W, Zheng Y, Okosi N, Wang Z, Su M (2018) Enhanced radiation shielding with conformal light-weight nanoparticle-polymer composite. ACS Appl Mater Interfaces 10(41):35510-35515

Lichtfouse E, Crini N, Fourmentin M, Zemmouri H, Queiroz L, Mohd Tadza MY, Picos Corrales L, Pei H, Wilson L, C. grégorio, (2019) Chitosan for direct bioflocculation of wastewater. Environ Chem Lett 17:10. https://doi.org/10.1007/s10311-019-00900-1

Liikanen M, Grönman K, Deviatkin I, Havukainen J, Hyvärinen M, Kärki T, Varis J, Soukka R, Horttanainen M (2019) Construction and demolition waste as a raw material for wood polymer composites-assessment of environmental impacts. J Clean Prod 225:716-727

Liu K, Piggott MR (1995) Shear strength of polymers and fibre composites: 1. thermoplastic and thermoset polymers. Composites 26:829-840. https://doi.org/10.1016/0010-4361(95)90876-2 
Lopes J, Martins M, Nogueira H, Estrada A, Trindade T (2021) Carbon-based heterogeneous photocatalysts for water cleaning technologies: a review. Environ Chem Lett. https://doi.org/10.1007/ s10311-020-01092-9

Luković J, Babić B, Bučevac D, Prekajski M, Pantić J, Baščarević Z, Matović B (2015) Synthesis and characterization of tungsten carbide fine powders. Ceram Int 41(1):1271-1277. https://doi. org/10.1016/j.ceramint.2014.09.057

Ma J, Qin G, Zhang Y, Sun J, Wang S, Jiang L (2018) Heavy metal removal from aqueous solutions by calcium silicate powder from waste coal fly-ash. J Clean Prod 182:776-782

Ma Z, Guo W, Yang R (2020) Performance evaluation of the polyurethane-based composites prepared with recycled polymer concrete aggregate. Materials 13:616. https://doi.org/10.3390/ ma13030616

Mahmoud ME, El-Khatib AM, Badawi MS, Rashad AR, El-Sharkawy RM, Thabet AA (2018a) Fabrication, characterization and gamma rays shielding properties of nano and micro lead oxidedispersed-high density polyethylene composites. Radiat Phys Chem 145:160-173. https://doi.org/10.1016/j.radphysche m.2017.10.017

Mahmoud ME, El-Khatib AM, Badawi MS, Rashad AR, El-Sharkawy RM, Thabet AA (2018b) Recycled high-density polyethylene plastics added with lead oxide nanoparticles as sustainable radiation shielding materials. J Clean Prod 176:276-287. https://doi. org/10.1016/j.jclepro.2017.12.100

Maity K, Garain S, Henkel K, Schmeißer D, Mandal D (2020) Selfpowered human-health monitoring through aligned pvdf nanofibers interfaced skin-interactive piezoelectric sensor. ACS Appl Polym Mater 2(2):862-878. https://doi.org/10.1021/acsap m.9b00846

Makvandi P, Iftekhar S, Pizzetti F, Zarepour A, Nazarzadeh Zare E, Ashrafizadeh M, Agarwal T, Padil V, Mohammadinejad R, Sillanpää M, Perale G, Zarrabi A, Rossi F (2020) Functionalization of polymers and nanomaterials for water treatment, food packaging, textile and biomedical applications: a review. Environ. Chem. Lett. https://doi.org/10.1007/s10311-020-01089-4

Mani V, Prasad N, Kelkar A (2016) Ultra high molecular weight polyethylene (UHMWPE) fiber epoxy composite hybridized with nanoparticles of gadolinium and boron for radiation shielding. In: SPIE optical engineering and applications, proceedings planetary defense and space environment applications

Manjunatha HC (2017) A study of gamma attenuation parameters in poly methyl methacrylate and Kapton. Radiat Phys Chem 137:254-259. https://doi.org/10.1016/j.radphysche m.2016.01.024

Mann K, Rani A, Heer M (2015a) Shielding behaviors of some polymer and plastic materials for gamma-rays. Radiat Phys Chem 106:247-254. https://doi.org/10.1016/j.radphysche m.2014.08.005

Mann KS, Rani A, Heer MS (2015b) Shielding behaviors of some polymer and plastic materials for gamma-rays. Radiat Phys Chem 106:247-254. https://doi.org/10.1016/j.radphysche m.2014.08.005

Mann HS, Brar GS, Mudahar GS (2016) Gamma-ray shielding effectiveness of novel light-weight clay-flyash bricks. Radiat Phys Chem 127:97-101. https://doi.org/10.1016/j.radphysche m.2016.06.013

Mao X, Wang L, Gu S, Duan Y, Zhu Y, Wang C, Lichtfouse E (2018) Synthesis of a three-dimensional network sodium alginatepoly(acrylic acid)/attapulgite hydrogel with good mechanic property and reusability for efficient adsorption of $\mathrm{Cu}^{2+}$ and $\mathrm{Pb}^{2+}$. Environ Chem Lett. https://doi.org/10.1007/s10311-018-0708-9

Marcelo LR, de Gois JS, da Silva AA, Cesar DV (2020) Synthesis of iron-based magnetic nanocomposites and applications in adsorption processes for water treatment: a review. Environ Chem Lett. https://doi.org/10.1007/s10311-020-01134-2

Marinkovic A, Radoman T, Dzunuzovic ES, Branko B, Balanc B, Spasojevic P (2013) Mechanical properties of composites based on unsaturated polyester resins obtained by chemical recycling of poly (ethylene terephthalate). Hem Ind 67(6):913-922

McMillan J (2019) Radiation shielding composites using thermoplastic polymers mouldable at low temperature. Phys Instrum Detect

Mirji R, Lobo B (2017a) Computation of the mass attenuation coefficient of polymeric materials at specific gamma photon energies. Radiat Phys Chem 135:32-44. https://doi.org/10.1016/j.radph yschem.2017.03.001

Mirji R, Lobo B (2017) Radiation shielding materials: a brief review on methods, scope and significance

Mirji R, Lobo B (2020) Study of polycarbonate-bismuth nitrate composite for shielding against gamma radiation. J Radioanal Nucl Chem 324(1):7-19. https://doi.org/10.1007/s10967-020-07038-3

Miskolczi N, Prof L, Bartha GD, Jóver B (2004) Thermal degradation of municipal plastic waste for production of fuel-like hydrocarbons. Polym Degrad Stab 86:357-366. https://doi.org/10.1016/j. polymdegradstab.2004.04.025

More CV, Lokhande RM, Pawar PP (2016) Effective atomic number and electron density of amino acids within the energy range of 0.122-1.330 MeV. Radiat Phys Chem 125:14-20

More CV, Bhosale RR, Pawar PP (2017) Detection of new polymer materials as gamma-ray-shielding materials. Radiat Eff Defects Solids 172(5-6):469-484. https://doi.org/10.1080/10420 150.2017 .1336765

More CV, Alavian H, Pawar PP (2020) Evaluation of gamma-ray attenuation characteristics of some thermoplastic polymers: Experimental, WinXCom and MCNPX studies. J Non-Cryst Solids 546:120277. https://doi.org/10.1016/j.jnoncrysol.2020.120277

More CV, Pawar PP, Badawi MS, Thabet AA (2020) Extensive theoretical study of gamma-ray shielding parameters using epoxy resin-metal chloride mixtures. Nucl Technol Radiat Prot 35(2):138-149

Mostafa AMA, Issa SAM, Sayyed MI (2017) Gamma ray shielding properties of $\mathrm{PbO}-\mathrm{B}_{2} \mathrm{O}_{3}-\mathrm{P}_{2} \mathrm{O}_{5}$ doped with $\mathrm{WO}_{3}$. J Alloys Compd 708:294-300. https://doi.org/10.1016/j.jallcom.2017.02.303

Mulenos George M, Liu J, Lujan H, Guo B, Lichtfouse E, Sharma V, Sayes C (2020) Copper, silver, and titania nanoparticles do not release ions under anoxic conditions and release only minute ion levels under oxic conditions in water: evidence for the low toxicity of nanoparticles. Environ Chem Lett. https://doi.org/10.1007/ s10311-020-00985-Z

Muthamma MV, Bubbly SG, Gudennavar SB, Narendranath KCS (2019) Poly(vinyl alcohol)-bismuth oxide composites for $\mathrm{X}$-ray and $\gamma$-ray shielding applications. J Appl Polym Sci 136(37):47949. https://doi.org/10.1002/app.47949

Nagaraja N, Manjunatha H, Seenappa L, Sridhar K, Ramalingam H (2020) Radiation shielding properties of silicon polymers. Radiat Phys Chem 171:108723

Nanda S, Berruti F (2020) Thermochemical conversion of plastic waste to fuels: a review. Environ CHEM Lett. https://doi.org/10.1007/ s10311-020-01094-7

Nasehi F, Ismail M (2019) Evaluation of X and gamma-rays attenuation parameters for polyacrylamide and $\mathrm{ZnO}$ composites as light shielding materials using MCNP and X-COM simulation. Nucl Med Radiat Ther 10(404):2

Nguyen M, Vu T, Nguyen T, Nguyen T, Ha Thuc N, Bui Q-B, Colin J, Perre P (2020) Synergistic influences of stearic acid coating and recycled PET microfibers on the enhanced properties of composite materials. Materials 13:1461. https://doi.org/10.3390/ma130 61461

Ninyong K, Wimolmala E, Sombatsompop N, Saenboonruang K (2019) Properties of natural rubber (NR) and wood/NR composites 
as gamma shielding materials. IOP Conf Ser Mater Sci Eng 526:012038. https://doi.org/10.1088/1757-899x/526/1/012038

Njuguna J, Pielichowski K, Alcock JR (2007) Epoxy-based fibre reinforced nanocomposites. Adv Eng Mater 9(10):835-847

Okamoto M (2003) Biodegradable polymer/layered silicate nanocomposites. In: Handbook of biodegrdable polymeric materials and their applications, pp 153-197

Olivera S, Chaitra K, Venkatesh K, Muralidhara H, Inamuddin I, Asiri AM, Ahamed M (2018) Cerium dioxide and composites for the removal of toxic metal ions. Environ Chem Lett. https ://doi.org/10.1007/s10311-018-0747-2

Osman A, Abdel-Monem A, Mansour Aly F (2015) Investigation the shielding properties of alumina reinforced composites. J Chem Bio Phy Sci Sec C 6:302-315

Oto B, Yildiz N, Akdemir F, Kavaz E (2015) Investigation of gamma radiation shielding properties of various ores. Prog Nucl Energy 85:391-403. https://doi.org/10.1016/j.pnuce ne.2015.07.016

Özdemir T, Güngör A, Akbay I, Uzun H, Babucçuoglu Y (2018) Nano lead oxide and epdm composite for development of polymer based radiation shielding material: gamma irradiation and attenuation tests. Radiat Phys Chem 144:248-255

Padervand M, Lichtfouse E, Robert D, Wang C (2020) Removal of microplastics from the environment: a review. Environ Chem Lett. https://doi.org/10.1007/s10311-020-00983-1

Parhi R (2020) Drug delivery applications of chitin and chitosan: a review. Environ Chem Lett. https://doi.org/10.1007/s10311-02000963-5

Pascoe RD (2003) Sorting of waste plastics for recycling. an introduction to automotive composites. K. L. Nick Tucker Rapra Technol Ltd 24:49-49

Pavlenko V, Cherkashina N, Yastrebinsky R (2019) Synthesis and radiation shielding properties of polyimide $/ \mathrm{Bi}_{2} \mathrm{O}_{3}$ composites. Heliyon 5(5):e01703

Phong NT, Gabr MH, Okubo K, Chuong B, Fujii T (2013) Enhancement of mechanical properties of carbon fabric/epoxy composites using micro/nano-sized bamboo fibrils. Mater Des 47:624-632. https://doi.org/10.1016/j.matdes.2012.12.057

Plionis AA, Garcia SR, Gonzales ER, Porterfield DR, Peterson DS (2009) Replacement of lead bricks with non-hazardous polymerbismuth for low-energy gamma shielding. J Radioanal Nucl Chem 282(1):239. https://doi.org/10.1007/s10967-009-0245-x

Puglia D, Kenny J (2018) Structure-property relationships of thermoset nanocomposites. In: Thermosets (second edition) structure, properties, and applications. Elsevier, pp 231-276

Qasim U, Ahmed A, Osman AA, Al-Muhtaseb A, Farrell C, Al-Abri M, Muzaffar R, Vo D-V, Vo N, Farrukh D, Rooney W (2020) Renewable cellulosic nanocomposites for food packaging to avoid fossil fuel plastic pollution: a review. Environ Chem Lett. https://doi.org/10.1007/s10311-020-01090-x

Qu P, Gao Y, Wu GF, Zhang LP (2010) Nanocomposites of Poly(lactic acid) reinforced with cellulose nanofibrils. BioResources 5:1811-1823

Rai M, Ingle A, Gupta I, Pandit R, Paralikar P, Gade A, Chaud M, Santos C (2018) Smart nanopackaging for the enhancement of food shelf life. Environ Chem Lett. https://doi.org/10.1007/s1031 1-018-0794-8

Rajendran B, Muthusamy S, Tos VC (2011) Mechanical and thermal propertiesss of unsaturated polyester/calcium carbonate nanocomposites. J Reinf Plast Compos 30(18):1549-1556

Ramli RA, Zakaria NZ, Rahman UUA, Bakhtiar NBA, Mustapha SNH, Lian YM (2018) Effect of mineral fillers on mechanical, thermal and morphological properties of kenaf recycled polyethylene wood plastic composite. Eur J Wood Products 76(6):1737-1743
Rani N, Vermani YK, Singh T (2020) Gamma radiation shielding properties of some Bi-Sn-Zn alloys. J Radiol Prot 40(1):296-310. https://doi.org/10.1088/1361-6498/ab6aaf

Rathi B, Ponnusamy SK (2020) Electrodeionization theory, mechanism and environmental applications: a review. Environ Chem Lett. https://doi.org/10.1007/s10311-020-01006-9

Rusmirović J, Trifkovic K, Bugarski B, Pavlović VB, Džunuzović J, Tomić M, Marinković AD (2016) High performance unsaturated polyester based nanocomposites: effect of vinyl modified nanosilica on mechanical properties. Express Polym Lett 10(2):139-159

Saiyad DM, Devashrayee N, Mewada R (2014) Study the effect of dispersion of filler in polymer composite for radiation shielding. Polym Compos. https://doi.org/10.1002/pc.22776

Şakar E, Büyükyıldız M, Alım B, Şakar BC, Kurudirek M (2019) Leaded brass alloys for gamma-ray shielding applications. Radiat Phys Chem 159:64-69

Salipira K, Mamba B, Krause R, Malefetse T, Durbach S (2007) Carbon nanotubes and cyclodextrin polymers for removing organic pollutants from water. Environ Chem Lett 5:13-17. https://doi. org/10.1007/s10311-006-0057-y

Sanjay M, Arpitha G, Laxmana Naik L, Gopalakrishna K, Yogesh B (2016) Studies on mechanical properties of banana/e-glass fabrics reinforced polyester hybrid composites. J Mater Environ Sci 7(9):3179-3192

Sathiyaraj S, Samuel JJ, Valeriano C, Kurudirek M (2017) Effective atomic number and buildup factor calculations for metal nano particle doped polymer gel. Vacuum. https://doi.org/10.1016/j. vacuum.2017.06.005

Sayyed MI (2016) Investigation of shielding parameters for smart polymers. Chin J Phys 54(3):408-415. https://doi.org/10.1016/j. cjph.2016.05.002

Sayyed MI, Lakshminarayana G, Kityk IV, Mahdi MA (2017) Evaluation of shielding parameters for heavy metal fluoride based tellurite-rich glasses for gamma ray shielding applications. Radiat Phys Chem 139:33-39. https://doi.org/10.1016/j.radphysche m.2017.05.013

Sayyed M, Lakshminarayana G, Mahdi M (2017) Evaluation of radiation shielding parameters for optical materials. Chalcogenide Lett 14(2):43-47

Sayyed MI, El-Mesady IA, Abouhaswa AS, Askin A, Rammah YS (2019) Comprehensive study on the structural, optical, physi$\mathrm{cal}$ and gamma photon shielding features of $\mathrm{B}_{2} \mathrm{O}_{3}-\mathrm{Bi}_{2} \mathrm{O}_{3}-\mathrm{PbO}-$ $\mathrm{TiO}_{2}$ glasses using WinXCOM and Geant4 code. J Mol Struct 1197:656-665. https://doi.org/10.1016/j.molstruc.2019.07.100

Sharma G, Thakur B, Naushad M, Kumar A, Stadler FJ, Alfadul SM, Mola GT (2018) Applications of nanocomposite hydrogels for biomedical engineering and environmental protection. Environ Chem Lett 16(1):113-146. https://doi.org/10.1007/s1031 1-017-0671-x

Sharma A, Singh B, Sandhu BS (2019) Investigation of photon interaction parameters of polymeric materials using Monte Carlo simulation. Chin J Phys 60:709-719. https://doi.org/10.1016/j. cjph.2019.06.011

Sharma A, Sayyed MI, Agar O, Kaçal MR, Polat H, Akman F (2020) Photon-shielding performance of bismuth oxychloride-filled polyester concretes. Mater Chem Phys 241:122330. https://doi. org/10.1016/j.matchemphys.2019.122330

Sheela M, Kamat VA, Kiran K, Eshwarappa K (2019) Preparation and characterization of bismuth-filled high-density polyethylene composites for gamma-ray shielding. Radiat Protect Environ 42(4): 180

Shent H, Pugh R, Forssberg E (1999) A review of plastics waste recycling and the flotation of plastics. Resour Conserv Recycl 25:85109. https://doi.org/10.1016/S0921-3449(98)00017-2 
Shi G, He LJ, Chen CZ, Liu JF, Liu QZ, Chen HY (2011) A novel nanocomposite based on recycled poly (ethylene terephthalate)/ ABS blends and nano-SiO $\mathrm{S}_{2}$. Adv Mater Res Trans Tech Publ

Shik NA, Gholamzadeh L (2018) X-ray shielding performance of the EPVC composites with micro-or nanoparticles of $\mathrm{WO}_{3}, \mathrm{PbO}$ or $\mathrm{Bi}_{2} \mathrm{O}_{3}$. Appl Radiat Isot 139:61-65

Siddiqui MTH, Nizamuddin S, Baloch HA, Mubarak NM, Dumbre DK, Inamuddin AM, Asiri AW, Bhutto MS, Griffin GJ (2018) Synthesis of magnetic carbon nanocomposites by hydrothermal carbonization and pyrolysis. Environ Chem Lett 16(3):821844. https://doi.org/10.1007/s10311-018-0724-9

Singh VP, Badiger N (2013) A comprehensive study on gamma-ray exposure build-up factors and fast neutron removal cross sections of fly-ash bricks. J Ceram 2013:1-13

Singh VP, Badiger NM, Kaewkhao J (2014) Radiation shielding competence of silicate and borate heavy metal oxide glasses: Comparative study. J Non-Cryst Solids 404:167-173. https:// doi.org/10.1016/j.jnoncrysol.2014.08.003

Singh VP, Badiger NM, Chanthima N, Kaewkhao J (2014) Evaluation of gamma-ray exposure buildup factors and neutron shielding for bismuth borosilicate glasses. Radiat Phys Chem 98:14-21. https://doi.org/10.1016/j.radphyschem.2013.12.029

Singh VP, Shirmardi SP, Medhat ME, Badiger NM (2015) Determination of mass attenuation coefficient for some polymers using Monte Carlo simulation. Vacuum 119:284-288. https:// doi.org/10.1016/j.vacuum.2015.06.006

Song R, Murphy M, Li C, Ting K, Soo C, Zheng Z (2018) Current development of biodegradable polymeric materials for biomedical applications. Drug Des Dev Ther 12:3117-3145. https://doi.org/10.2147/DDDT.S165440

Sorrentino A, Gorrasi G, Lichtfouse E (2020) Back to plastic pollution in COVID times. Environ Chem Lett. https://doi. org/10.1007/s10311-020-01129-z

Soundharraj P, Dhinasekaran D, Lichtfouse E (2020) Plant-derived silica nanoparticles and composites for biosensors, bioimaging, drug delivery and supercapacitors: a review. Environ Chem Lett. https://doi.org/10.1007/s10311-020-01123-5

Soylu H, Lambrecht FY, Ersöz O (2015) Gamma radiation shielding efficiency of a new lead-free composite material. J Radioanal Nucl Chem 305(2):529-534

Srinivasan K, Samuel E (2017) Evaluation of radiation shielding properties of the polyvinyl alcohol/iron oxide polymer composite. Med Phys 42(4):273-278. https://doi.org/10.4103/jmp. JMP_54_17

Surendhiran D, Sirajunnisa A, Tamilselvam K (2017) Silvermagnetic nanocomposites for water purification. Environ Chem Lett 15(3):367-386. https://doi.org/10.1007/s1031 1-017-0635-1

Suteau C, Chiron M (2005) An iterative method for calculating gamma-ray build-up factors in multi-layer shields. Radiat Prot Dosimetry 116(1-4 Pt 2):489-492. https://doi.org/10.1093/ $\mathrm{rpd} / \mathrm{nci} 192$

Taylor JJ (1954) Application of gamma ray build-up data to shield design, Westinghouse Electric, Corporation Atomic Power, Division U. S. Atomic Energy Commission, Bettis Atomic Power, Laboratory

Tekin HO, Issa S (2018) Gamma radiation shielding properties of the hematite-serpentine concrete blended with $\mathrm{WO}_{3}$ and $\mathrm{Bi}_{2} \mathrm{O}_{3}$ micro and nano particles using MCNPX code. Radiat Phys Chem. https://doi.org/10.1016/j.radphyschem.2018.05.002

Thuyavan YL, Anantharaman N, Arthanareeswaran G, Ismail AF, Mangalaraja RV (2015) Preparation and characterization of $\mathrm{TiO}_{2}$-sulfonated polymer embedded polyetherimide membranes for effective desalination application. Desalination 365:355-364. https://doi.org/10.1016/j.desal.2015.03.004
Tian X, Liu T, Qingrui W, Abliz D, Ziegmann G (2016) Recycling and remanufacturing of 3D printed continuous carbon fiber reinforced PLA composites. J Clean Prod. https://doi. org/10.1016/j.jclepro.2016.11.139

Tofa T, Laxman K, Paul S, Dutta J (2019) Visible light photocatalytic degradation of microplastic residues with zinc oxide nanorods. Environ Chem Lett 17:1341-1346. https://doi.org/10.1007/ s10311-019-00859-z

Tsepelev A, Kiseleva T, Zholudev S, Ковалева C, Grigoryeva T, Ivanenko I, Devyatkina E, Ilyushin A, Lyakhov N (2019) Electron irradiation resistance of the composite material structure based on ultra-high molecular polyethylene and boron carbide. J Phys Conf Ser 1347:012028. https://doi.org/10.1088/17426596/1347/1/012028

Turner TA, Pickering SJ, Warrior NA (2011) Development of recycled carbon fibre moulding compounds-preparation of waste composites. Compos B Eng 42(3):517-525. https://doi. org/10.1016/j.compositesb.2010.11.010

Vahabi SM, Shamsaie Zafarghandi M (2020) Build-up factors for water and soft tissue by MCNP using a co-centric multilayer model: comparative study. J Instrum 15:P05018. https://doi. org/10.1088/1748-0221/15/05/p05018

Vahabi SM, Bahreinipour M, Shamsaie Zafarghandi M (2017) Determining the mass attenuation coefficients for some polymers using MCNP code: a comparison study. Vacuum 136:73-76. https://doi.org/10.1016/j.vacuum.2016.11.011

Vilkov F, Lozovan A, Bazhanov A, Kasitsyn A, Schekoturova O, Solovev M (2017) Investigation of the radiation-protective properties of a highly filled liquid glass material. J Surf Investig X-ray Synchrotron Neutron Tech 11(5):912-916

Wady P, Wasilewski A, Brock L, Edge R, Baidak A, McBride C, Leay L, Griffiths A, Vallés C (2019) Effect of ionising radiation on the mechanical and structural properties of 3D printed plastics. Addit Manuf 31:100907. https://doi.org/10.1016/j. addma.2019.100907

Wang H, Zhang H, Su Y, Liu T, Yu H, Yang Y, Li X, Guo B (2015) Preparation and radiation shielding properties of Gd2O3/PEEK composites. Polym Compos 36(4):651-659

Wen Y, Yuan J, Ma X, Wang S, Liu Y (2019) Polymeric nanocomposite membranes for water treatment: a review. Environ Chem Lett. https://doi.org/10.1007/s10311-019-00895-9

Woodhead DJJORP (2002) Protection of the environment from the effects of ionising radiation. J Radiol Prot 22(3):231

Wozniak AI, Ivanov VS, Zhdanovich OA, Nazarov VI, Yegorov AS (2017) Modern approaches to polymer materials protecting from ionizing radiation. Orient J Chem 33(5):2148-2163

Wu Y, Cao Y, Wu Y, Li DJM (2020) Mechanical properties and gamma-ray shielding performance of 3D-printed poly-etherether-ketone/tungsten composites. Materials 13(20):4475

Yildirim Y, Oral A (2018) Structural changes in Poly(lactic acid)zeolite nanocomposites exposed to 60 Co gamma rays. Radiat Eff Defects Solids 173:1-11. https://doi.org/10.1080/10420 150.2018.1462367

Y1lmaz E, Baltas H, Kırıs E, Ustabas İ, Cevik U, El-Khayatt A (2011) Gamma ray and neutron shielding properties of some concrete materials. Ann Nucl Energy 38(10):2204-2212

Yurt Lambrecht F, Ersoz OA, Soylu HM (2016) Tungsten-ethylene vinyl acetate (EVA) composite as a gamma rays shielding material. Indian J Pure Appl Phys 54(12):793-796

Zadegan S, Hosainalipour M, Rezaie H, Ghassai H, Shokrgozar M (2011) Synthesis and biocompatibility evaluation of cellulose/ hydroxyapatite nanocomposite scaffold in 1-n-allyl-3-methylimidazolium chloride. Mater Sci Eng C 31:954-961. https:// doi.org/10.1016/j.msec.2011.02.021 
Zeng Q, Wang D, Yu A, Lu G (2002) Synthesis of polymer-montmorillonite nanocomposites by in situ intercalative polymerization. Nanotechnology 13(5):549

Zezin AA, Fel'dman VI, Egorov AV, Shmakova NA (2004) Effect of crystallinity degree on formation of radical ions in irradiated isotactic polystyrene. Dokl Chem 394(5):631-635

Zhong W, Sui G, Jana S, Miller J (2009) Cosmic radiation shielding tests for UHMWPE fiber/nano-epoxy composites. Compos Sci Technol 69:2093-2097. https://doi.org/10.1016/j.compscitec h.2008.10.004
Zhou K, Gong K, Zhou Q, Zhao S, Guo H, Qian X (2020) Estimating the feasibility of using industrial solid wastes as raw material for polyurethane composites with low fire hazards. J Clean Prod 257:120606. https://doi.org/10.1016/j.jclepro.2020.12060 6

Zulkifli NI, Samat N, Anuar H, Zainuddin N (2015) Mechanical properties and failure modes of recycled polypropylene/microcrystalline cellulose composites. Mater Des 69:114-123

Publisher's Note Springer Nature remains neutral with regard to jurisdictional claims in published maps and institutional affiliations. 